\title{
Job Creation by Company Size Class: Concentration and Persistence of Job Gains and Losses in Canadian Companies
}

\section{Research Paper \#93}

\author{
by \\ Garnett Picot \\ Richard Dupuy \\ Business and Labour Market \\ Analysis Division
}

Statistics Canada

April, 1996 


\section{Abstract}

The statistical observation that small firms have created the majority of new jobs during the 1980s has had a tremendous influence on public policy. Governments have looked to the small firm sector for employment growth, and have promoted policies to augment this expansion. However, recent research in the US suggests that net job creation in the small firm sector may have been overestimated, relative to that in large firms.

The first part of this paper addresses various measurement issues raised in the recent research, and uses a very unique Canadian longitudinal data set that encompasses all companies in the Canadian economy to reassess the issue of job creation by firm size. We conclude that over the 1978-92 period, for both the entire Canadian economy and the manufacturing sector, the growth rate of net and gross employment decreases monotonically as the size of firm increases, no matter which method of sizing firms is used. Measurement does matter, however, as the magnitude of the difference in the growth rates of small and large firms is very sensitive to the measurement approaches used. Part one of the paper also produces results for various industrial sectors, and examines employment growth in existing small and large firms (i.e., excluding births). It is found that employment growth in the population of existing small and large firms is very similar. Finally attempts are made to introduce a job quality aspect to the numbers by using payroll distributions rather than employment. The net and gross rates of increase and decrease in payrolls by firm size are found to be only marginally different than those of employment.

The second part of the paper looks at concentration of employment creation and destruction within size classes. This is relevant because if growth is highly concentrated, knowing that a firm is small will provide little information about its prospects for growth. Most small firms would grow relatively little, or decline, while a few expanded a lot. It is found that both job creation and destruction is highly concentrated among relatively few firms in all size groups, but it is greater among small and mid-sized companies than large. Finally attempts are made to correlate the performance of businesses over two three-year periods. It is found that knowing that a firm is a high performer (in terms of jobs created) over one period is of only limited value in determining growth in the second period. This is particularly true among small firms. These results suggest that firms which expand rapidly during one period are replaced to some considerable degree by others in the subsequent period.

Keywords: Job Creation, Employment Growth, Firm-Size, Longitudinal, Concentration, Payrolls. 


\section{Introduction}

The statistical observation that small firms have created the majority of new jobs during the 1980s has had a tremendous impact on public policy. Few other statistical facts could claim such influence. With persistently high unemployment during the 1980s and early 1990s, governments seeking employment growth have turned to the sector that was apparently the generator of most jobs.

This has resulted in a public policy orientation that has very actively promoted the development and expansion of small firms through various means, including differential tax treatment, the provision of information support services, the creation of sources of venture capital, and the exclusion of small firms from various legislation, such as the requirement in some provinces to equalize fringe benefits for full-time and part-time staff (Industry Canada, 1994). One major rationale for this policy orientation has been the belief that if the Canadian economy is to achieve a substantial growth in employment, it will be among small and medium sized firms.

The roots of this belief lie with work by the American economist David Birch $(1979,1987)$, in which he found that most of net new job creation was among small firms. Other studies have also concluded that in many countries small firms have dominated employment creation in the recent past (Loveman and Sengenberger, 1991; OECD, 1985). In Canada, various publications, including the Annual Report on Small Business in Ontario (1987) and Small Business in Canada (1991), ascribed $80 \%$ to $90 \%$ of total net new jobs in Canada to small (under 50 employees) firms. Asking the somewhat more limited question of whether there has been a shift in the distribution of employment by firm size in Canada over the late 1970s and 1980s, Wannell (1991) concludes that the answer is yes; small firms now account for a greater share of all employment than in previous years.

These results are of interest for numerous reasons other than the concern with job creation. The shift in employment towards small firms also potentially bears on the rising earnings inequality observed in North American labour markets, and the quality of jobs produced. As noted in Morissette (1993) and Brown, Hamilton and Medoff (1990), jobs in small firms pay less on average, even after controlling for differences in worker characteristics, have fewer fringe benefits, are shorter in duration, and are more likely to lead to permanent layoffs (Picot, 1992). In addition, numerous explanations are developing to explain the job creation strength of small firms, such as the availability of flexible specialized technologies that allow small firms to respond to market needs quickly, or the labour cost advantages associated with lower wages. The more rapid employment growth in small firms is of interest for many reasons.

But other analyses have for some time cast doubt on a number of aspects of this apparent relationship between employment growth and firm size. Leonard (1986) points out that much, if not all, of the observation that small firms account for most employment creation in U.S. manufacturing could simply be the result of a very large transient component of employment change associated with the regression to the mean phenomenon. More recently Davis, Haltiwanger and Schuh (1993) demonstrate that when various means are used to overcome the influence of the transient component of employment change on the results, the differences in employment growth between small and large establishments in the U.S. manufacturing sector disappears. 
The first goal of this paper is to review the recent evidence that has been produced in Canada regarding the effect of measurement issues on the question of job creation by firm size. After attempting to, in particular, reduce the influence of the transient component of employment change associated with a short-term regression to the mean phenomenon, we re-ask the question of whether a disproportionate share of job creation is observed among small firms. The short answer is, in Canada, yes.

But even if a disproportionate share of job creation has been observed in the small firm sector, there remains numerous important empirical questions that would influence policy. The second goal of this paper is to extend the earlier work and ask additional questions regarding the nature of employment creation in the small firm sector in particular. The first issue addressed relates to potential changes in relative job quality between large and small firms. Most studies rely on a headcount employment measure, including those mentioned above. But if relative wages or hours worked are changing between small and large firms, the results based on headcounts alone would not reflect such changes. Accounting for changing relative wages or hours worked provides a more informative result.

A second issue relates to the use of averages. Reported job creation and loss rates by firm size are typically averages. They have the potential to be misleading, as at some superficial level one is left with the impression that some 'typical', say, small firm behaves in this way. But there are few 'typical' firms. In other economies it has been observed that job growth is highly concentrated among few firms (Haltiwanger, Davis, and Schuh, 1994, Blanchflower and Burgess, 1994). We ask just how concentrated job creation and destruction is in the small firm (and other) sectors in the Canadian economy. Just how much variation is there in the job creation performance of small (and large) firms?

Finally, having identified the high performing small (or large) firms in any given period, what does this tell us about their future performance regarding job gains or losses? Is there any useful longer term information in knowing which firms have been the greatest job creators, or is the transient component of employment change at the firm level so great that it swamps longer term trends?

The principal data source is LEAP (Longitudinal Employment Analysis Program), which is a longitudinal file of companies (legal entities) spanning the period 1978 to 1992. It contains annual employment data for each company, and is described in the appendix. In an earlier paper, Baldwin and Picot (1995) addressed the issue of the role of small manufacturing establishments in job creation in Canada. This paper extends that to the entire economy using company level data, and also addresses the additional issues of concentration of job creation, and the longer term performance of high performing firms. 


\section{Part I: Differences in Average Job Gain, Loss and Employment Growth in the Small and Large Unit Sectors}

This first section addresses a number of methodological issues in the measurement of average job gain and loss in the sectors defined by size . But first it is necessary to define job change. Job gain and loss is measured in the manner used in the majority of earlier studies. Job gain is the increase in employment observed in expanding continuing firms, or newly identified companies (births). Job loss is the decline in employment in contracting continuing firms, or no-longer identified companies (deaths). Net job change is the difference between job gain and loss. Growth rates are calculated by dividing these numbers by total employment in the size class ${ }^{1}$.

\section{The Results Using Alternative Measures of Firm Size}

\section{Using Longitudinal Company Level Data for the Entire Commercial Economy ${ }^{2}$}

One can think of employment change at the firm level of consisting of a long-run trend and a short term, transitory component. It has been shown that much of the employment change in individual establishments is in fact transitory, and will be reversed in the short run (Baldwin and Gorecki, 1990; Davis, Haltiwanger and Schuh, 1993). These transitory movements can influence the results in analysis of employment change by firm size. A large transitory component can result in inappropriate measures of firm size, as pointed out in Davis, Haltiwanger and Schuh (1994) ${ }^{3}$. It can also affect the measured employment change of the firm between years. This section deals with its impact on the sizing of firms.

The result can be that smaller firms appear to create large numbers of jobs, and larger firms lose large numbers, even if their longer run growth trends are not dissimilar. To at least partially overcome this possibility, three different measures of firm size are employed. Longitudinal data on employment in all companies (legal entities) in the commercial economy in Canada over the 1978 to 1992 period are used. The essence of these alternative measures of firm size is to average

1 While alternative measures of size of firm are used in this paper, in all cases the change in employment between consecutive years is calculated as $[\mathrm{E}(\mathrm{t}+1)-\mathrm{E}(\mathrm{t})] / \mathrm{E}(\mathrm{t})$, where $\mathrm{E}(\mathrm{t})$ is the employment in the base year $\mathrm{t}$. There are other ways of calculating employment change, such as replacing the denominator in the previous formula with the method used to calculate size. For example, if size was calculated as $[\mathrm{E}(\mathrm{t}+1)+\mathrm{E}(\mathrm{t})] / 2$ then employment change would be $[\mathrm{E}(\mathrm{t}+1)-\mathrm{E}(\mathrm{t})] /[[\mathrm{E}(\mathrm{t}+1)+\mathrm{E}(\mathrm{t})] / 2]$. We calculated employment change using this alternative method, and found that the results were not significantly different from those using the simple employment change formula outlined above. Thus we used the more straightforward approach.

2 Excluding the agriculture, health, education and government sectors

3 When observed at the peak of the transitory movement the firm will have a greater likelihood of being classified as a large firm than in other years, and it will tend to be facing a transitory decline. Similarly, when observed at the trough of this transitory movement, when it is more likely to be classified as a smaller firm, the firm will tend to be facing a (transitory) increase in employment. Because of this, firms which tend to be classified as large in the base year (t1), will tend to be facing an employment decline, and firms which tend to be classified as small will tend to be facing an employment increase. And to the extent that this is transitory, it is misleading, since the long run employment level of the firm may not be changing. We would have observed, however, that the smaller the firm, the greater the tendency to create employment. 
employment in the company over two or more years, thus reducing the transitory component. This work follows the approach employed by Davis, Haltiwanger and Schuh (1994). The alternative measures of employment used to establish firm size include (1) base year employment (a measure which does not attempt to dampen the effect of transitory employment movements on the classification of firms by size), (2) current average size, which is the average firm size in years $\mathrm{t}$ (the first year of the period) and $\mathrm{t}+1$, and (3) the long run average, which in this case is the average firm size over the period 1978 to 1988.

There are two basic findings. First, the choice of the measure of firm size has a very large effect on the results. Second, no matter which measure is employed, both gross job gain and gross job loss are concentrated among the small firm sector, and the rate of job gain and loss decreases monotonically as size increases. These results are shown in table 1.

\begin{tabular}{|c|c|c|c|c|}
\hline FIRM SIZE & JOB GAIN RATE & JOB LOSS RATE & $\begin{array}{c}\text { NET JOB CHANGE } \\
\text { RATE }\end{array}$ & $\begin{array}{c}\text { EMPLOYMENT } \\
\text { DISTRIBUTION } \\
\text { \% OF ALU'S IN SIZE } \\
\text { CLASS } \\
\end{array}$ \\
\hline & \multicolumn{4}{|c|}{ BASE YEAR } \\
\hline $0-19$ & 26.7 & -18.6 & 8.1 & 24.0 \\
\hline $20-49$ & 14.9 & -14.6 & 0.3 & 11.9 \\
\hline $50-99$ & 13.0 & -13.8 & -0.7 & 8.3 \\
\hline $100-499$ & 11.1 & -11.9 & -0.8 & 16.0 \\
\hline $500+$ & 5.9 & -7.1 & -1.2 & 39.7 \\
\hline \multirow[t]{2}{*}{ TOTAL } & 13.4 & -12.1 & 1.3 & 100.0 \\
\hline & \multicolumn{4}{|c|}{ AVERAGE CURRENT SIZE } \\
\hline $0-19$ & 23.4 & -20.2 & 3.3 & 24.2 \\
\hline $20-49$ & 15.9 & -14.2 & 1.7 & 11.9 \\
\hline $50-99$ & 14.4 & -13.0 & 1.4 & 8.3 \\
\hline $100-499$ & 12.2 & -11.2 & 1.0 & 16.0 \\
\hline $500+$ & 6.8 & -6.6 & 0.1 & 39.6 \\
\hline \multirow[t]{2}{*}{ TOTAL } & 13.4 & -12.1 & 1.3 & 100.0 \\
\hline & \multicolumn{4}{|c|}{ LONG RUN AVERAGE SIZE (1978-88) } \\
\hline $0-19$ & 23.5 & -18.4 & 5.1 & 23.7 \\
\hline $20-49$ & 17.0 & -12.6 & 4.5 & 10.9 \\
\hline $50-99$ & 15.1 & -11.2 & 3.8 & 7.9 \\
\hline $100-499$ & 12.2 & -9.9 & 2.3 & 15.9 \\
\hline $500+$ & 6.1 & -5.4 & 0.6 & 41.6 \\
\hline TOTAL & $\mathbf{1 3 . 1}$ & -10.5 & 2.6 & 100.0 \\
\hline
\end{tabular}

These findings can be expressed in terms of the distribution of gross job gain, loss and net change over the period, as shown in chart 1 . With about one-quarter of employment, companies with fewer than 20 employees accounted for between $42 \%$ and $48 \%$ of the gross average annual job gain between 1978 and 1992, depending on which measure of firm size is employed. They also accounted for between $37 \%$ and $40 \%$ of gross average annual job loss. Thus, both job gain and job loss were concentrated in the small firm sector over the past decade or so in Canada. 
CHART 1: DISTRIBUTION OF EMPLOYMENT, JOB GAIN AND JOB LOSS, BY FIRM SIZE, AVERAGE 1978-92

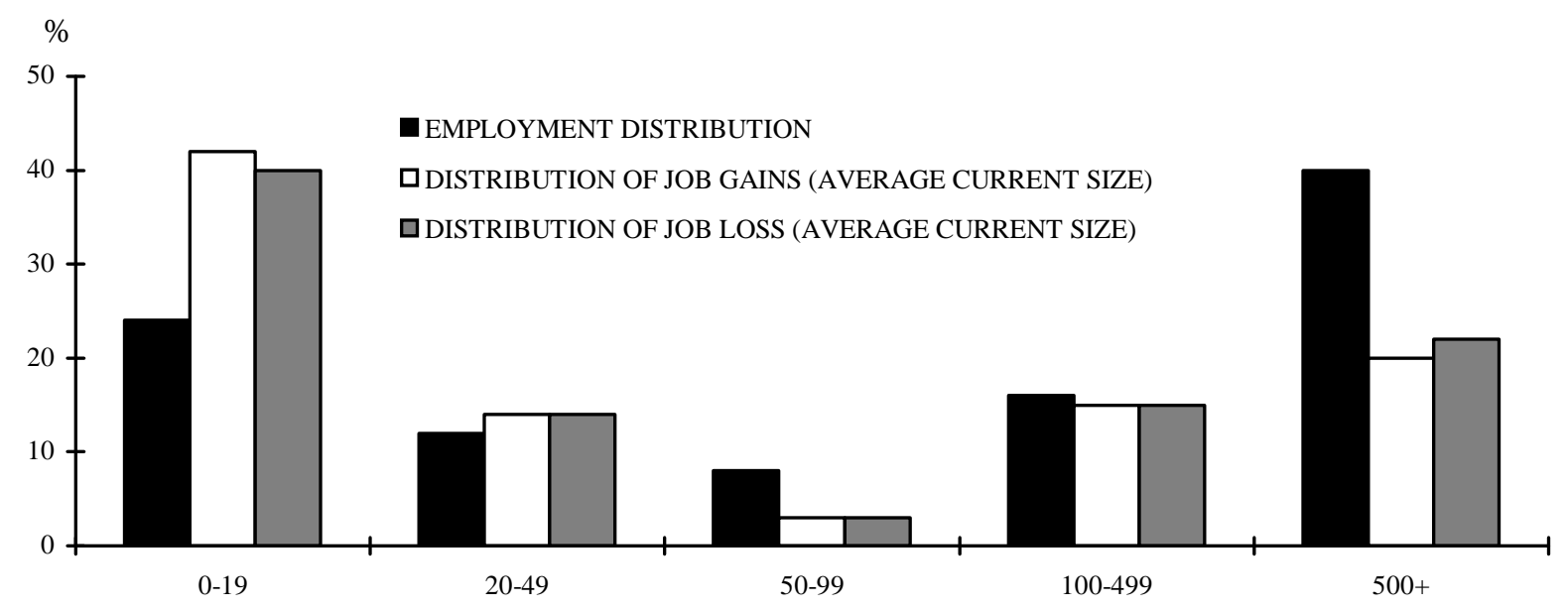

Such concentration was not observed among somewhat larger companies, however. Those with employment between 20 and 500, with about 36\% of employment, accounted for about the same amount of job loss and job gain over the period (between $34 \%$ and $38 \%$ of gross job gain, and $38 \%$ to $40 \%$ of gross job loss).

Turning to employment growth (net job change rate), employment among small firms grew at an average of between $3.3 \%$ and $8.1 \%$ annually over the period, depending on the measure of firm size employed. Among large firms (over 500 employees), average employment growth was estimated to be between $-1.2 \%$ and $0.1 \%$. The average annual growth rate in net employment declined monotonically, no matter which measure of firm size is employed (table 1), as does the net number of jobs created (chart 2). The differences in the estimated growth rates when using different measures of firm size are large, however, indicating these measurement issues are important.

CHART 2: AVERAGE ANNUAL NET CHANGE IN EMPLOYMENT, 1978-92

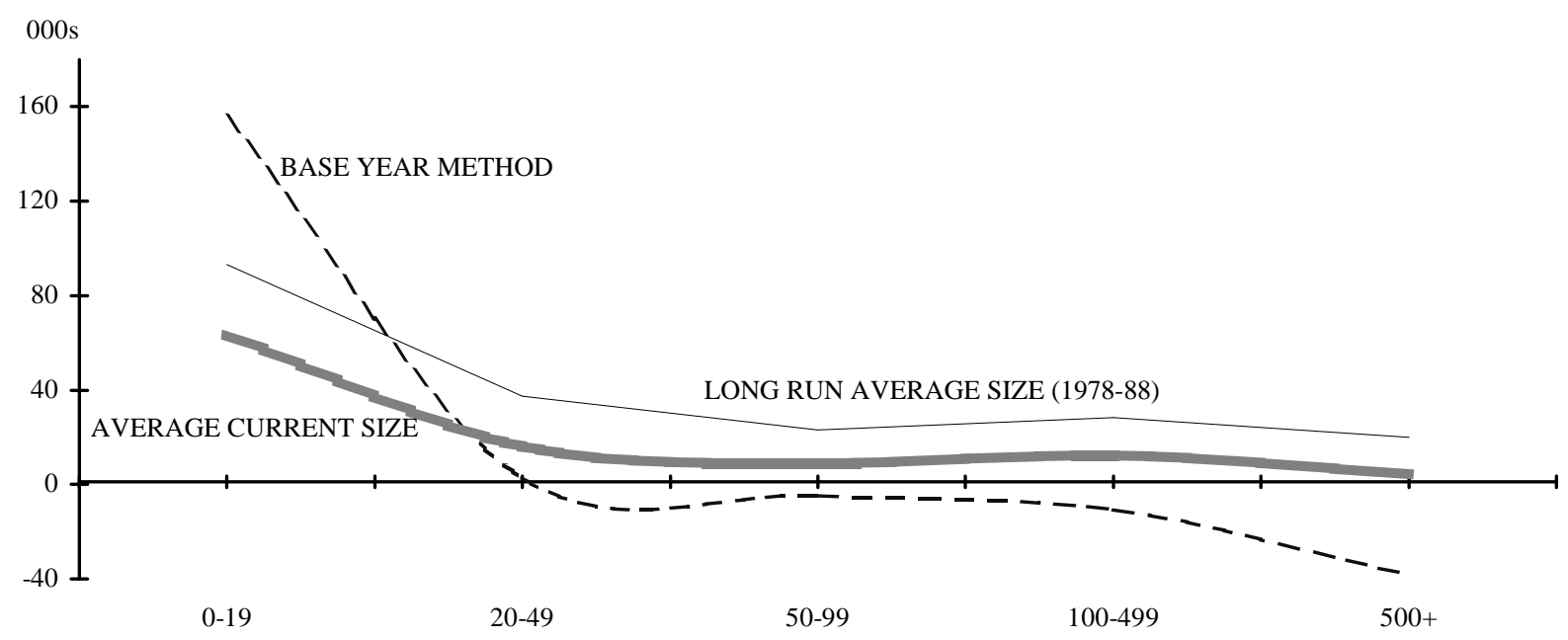




\section{Using Longitudinal Establishment Level Data for Manufacturing}

Another study, using a different longitudinal data set on establishments in the manufacturing sector over the 1970 to 1990 period found results similar to those reported above. Baldwin and Picot (1995) sized establishments using five different methods, four of which were intended to overcome to some extent the effect of transitory employment change on establishment size. The measures were very similar to those outlined above. Again both gross job gain and gross job loss were concentrated among small establishments, as rates were higher. Establishments under 50 employees had job gain rates from $18 \%$ to $30 \%$, compared to $4 \%$ to $7 \%$ among establishments over 500, depending on the size and measure used. Gross job loss rates had similar differences ( $14 \%$ to $22 \%$ among the smaller establishments, $4 \%$ to $7 \%$ among the larger).

Average annual employment growth (net job change) between 1970 and 1990 ranged from $7 \%$ to $11 \%$ among establishments under 20 to 0 to $-2.2 \%$ among establishments over $500^{4}$. Again, the manner in which establishment size was determined did significantly influence the results, but in all cases gross job gain, loss, and net change were, on average, higher among smaller establishments.

The similarities in this data set with that employed by numerous researchers in the U.S. for that country, including Davis, Haltiwanger and Schuh (1994), make comparisons between the two countries possible. This is a fairly rare possibility, as generally the longitudinal data sources used in different countries for job creation and destruction analyses are sufficiently different so as to make comparisons difficult. For example, there is no data set in the U.S. which corresponds to the LEAP longitudinal file of companies used above. Hence, there is no way of knowing if the results reported above are comparable to those that would be found for the U.S.

It is possible to compare the results for establishments in the manufacturing sector in the two countries, however. Generally speaking, Baldwin and Picot (1995) find that the gross job gain rate is higher among small Canadian than American plants, resulting in employment growth (net job change) being higher in small Canadian than American manufacturing plants. In essence, corrections for the undesirable effect of transitory employment movements on the determination of plant size fundamentally changes the conclusions in the U.S., but not in Canada. The extent to which jobs are observed to be disproportionately created among small plants is greatly reduced when the corrections referred to earlier are applied, but the observation remains nonetheless in the Canadian manufacturing sector.

\section{Longer Run Change in Employment in Business Units}

Just as short run transitory movement in employment can create issues in sizing firms, so too can it create problems in measuring employment change at the firm or plant level. When measuring employment change between two years, as was done in all the work reported up to this point, if the transitory component is large, and the long run trend component small, the former will

4 When using the full period average plant size for continuing establishments (that is, using the average of the establishment size over the entire 1970 to 1990 period to establish plant size), the differential in the net employment growth rate by size is substantially reduced. While small establishments display a positive net employment growth rate, so do very large (2500 to 5000) establishments. 
dominate the calculations. Such job gain or loss may be reversed the following year. This is still job creation (or destruction) and is of interest, but it is not a reflection of the longer term job creation/destruction roles of small or large firms.

Job change over a number of years was calculated for each business unit. Over a longer period the significance of the short-run transitory component on the results will diminish, that of the longerrun employment trend increase ${ }^{5}$.

These adjustments do not change the fundamental conclusions reached earlier. Among Canadian companies in the commercial economy as a whole, both job gain and loss are concentrated among the small firm sector. For example, when measuring change in employment between 1984 and 1988 for each company, and sizing using the average size over that entire period, $40 \%$ of job gain and $41 \%$ of job loss are accounted for by companies with under 20 employees, which represent $23 \%$ of employment over the period. Net employment grew by about $35 \%$ over this period for these companies, compared to $6 \%$ in companies with more than 500 employees (chart 3). As before, the disproportionate growth is really among the smaller companies, in particular those under 20 employees, not the medium sized companies, say 50 to 500 . For this latter group their share of job gain and job loss is very similar to their share of employment in the economy.

\section{CHART 3: JOB GAIN \& LOSS RATES AND NET EMPLOYMENT CHANGES, 1984-88, SIZING USING AVERAGES OVER ENTIRE PERIOD}

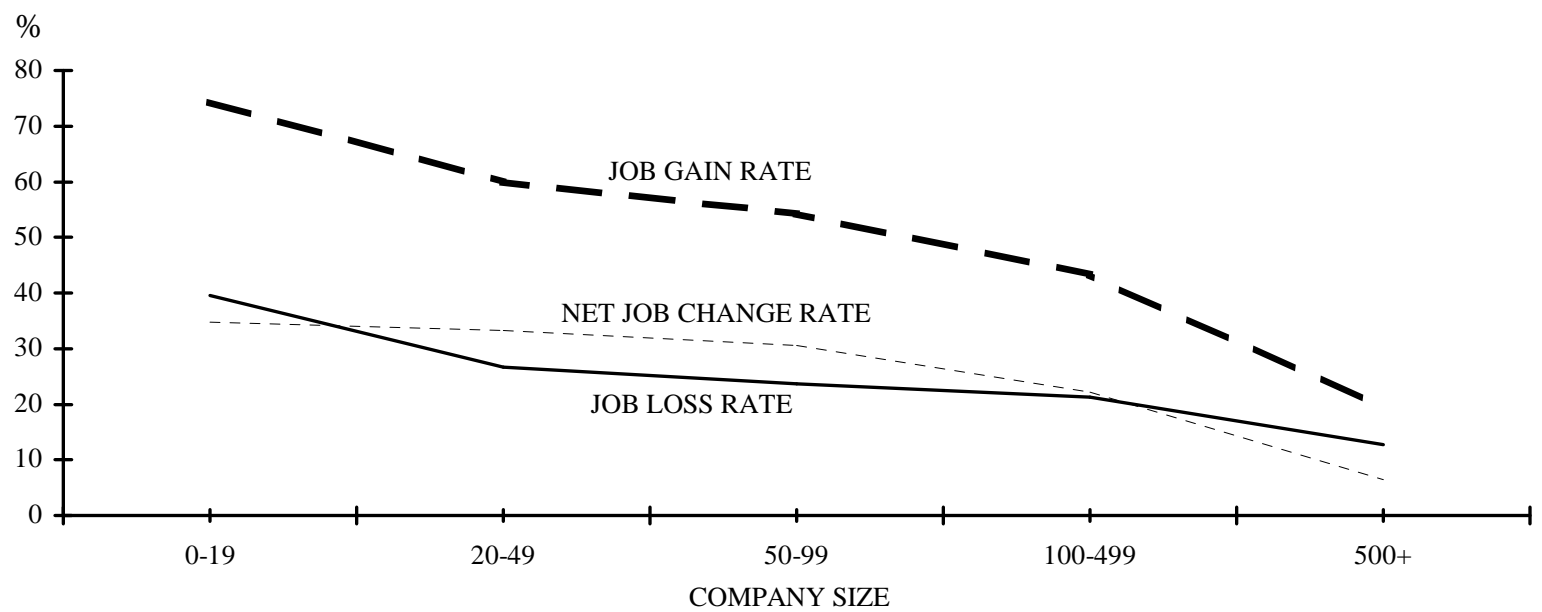

Similar approaches were used in the analysis of employment in establishments in the manufacturing sector, with similar results. Gross job creation, destruction and net employment growth were all higher among small than large manufacturing plants when longer run measures of employment change are used.

5 Various alternative measures of firm size...including the average during the first two years of the period, and the average over the entire period...are used for the reasons discussed earlier. 


\section{Do These Results Hold for All Industrial Sectors?}

The answer is basically yes ${ }^{6}$. Differences among industrial sectors in employment creation by company size can be determined from the LEAP data. As for the economy as a whole, both job gain and loss rates are higher in small than large firms in all six major industrial sectors used in this work. The growth in net employment (the difference between the job gain and loss rates) is clearly greater among small than large firms in the goods sector, including the primary, manufacturing and construction industries, and declines monotonically with size (table 2). In fact, net growth in employment over the 1978 to 1992 period was negative (in the $-1 \%$ to $-3 \%$ range annually) among large firms in all the goods industries and distributive services ${ }^{7}$. In these sectors, net employment in small firms grew in the $1.5 \%$ to $3.2 \%$ range.

\begin{tabular}{|c|c|c|c|c|c|c|c|}
\hline $\begin{array}{l}\text { FIRM } \\
\text { SIZE }\end{array}$ & $\begin{array}{l}\text { TOTAL } \\
\text { COMMERCIAL } \\
\text { ECONOMY }\end{array}$ & PRIMARY & MANUFACTURING & CONSTRUCTION & $\begin{array}{l}\text { DISTRIBUTIVE } \\
\text { SERVICES }\end{array}$ & $\begin{array}{l}\text { CONSUMER } \\
\text { SERVICES }\end{array}$ & $\begin{array}{l}\text { BUSINESS } \\
\text { SERVICES }\end{array}$ \\
\hline & \multicolumn{7}{|c|}{ USING THE CURRENT AVERAGE SIZE METHOD OF SIZING FIRMS } \\
\hline & \multicolumn{7}{|c|}{ JOB GAIN RATE (\%) } \\
\hline $0-19$ & 23.4 & 27.6 & 23.2 & 24.4 & 20.8 & 23.1 & 25.5 \\
\hline $20-49$ & 15.9 & 18.0 & 14.4 & 15.9 & 13.8 & 16.1 & 20.2 \\
\hline $50-99$ & 14.4 & 16.8 & 12.1 & 17.9 & 12.6 & 14.7 & 18.2 \\
\hline $100-499$ & 12.2 & 13.6 & 9.8 & 16.6 & 10.7 & 13.7 & 14.8 \\
\hline $500+$ & 6.8 & 6.4 & 5.4 & 14.1 & 5.7 & 8.5 & 7.7 \\
\hline \multirow[t]{3}{*}{ TOTAL } & 13.4 & 12.7 & 9.4 & 20.2 & 10.9 & 15.9 & 15.1 \\
\hline & & & & & & & \\
\hline & \multicolumn{7}{|c|}{ JOB LOSS RATE (\%) } \\
\hline $0-19$ & -20.2 & -24.9 & -20.0 & -22.9 & -18.2 & -19.3 & -21.7 \\
\hline $20-49$ & -14.2 & -16.9 & -14.4 & -16.2 & -13.1 & -12.8 & -17.6 \\
\hline $50-99$ & -13.0 & -17.6 & -12.0 & -18.0 & -12.0 & -11.5 & -16.6 \\
\hline $100-499$ & -11.2 & -14.9 & -10.3 & -17.4 & -10.0 & -10.5 & -12.8 \\
\hline $500+$ & -6.6 & -7.7 & -7.5 & -16.9 & -5.9 & -6.2 & -5.5 \\
\hline \multirow[t]{2}{*}{ TOTAL } & -12.1 & -13.1 & -10.3 & -19.9 & -10.2 & -12.7 & -12.5 \\
\hline & \multicolumn{7}{|c|}{ NET JOB CHANGE RATE } \\
\hline $0-19$ & 3.3 & 2.7 & 3.2 & 1.5 & 2.7 & 3.8 & 3.8 \\
\hline $20-49$ & 1.7 & 1.0 & -0.1 & -0.4 & 0.8 & 3.3 & 2.5 \\
\hline $50-99$ & 1.4 & -0.7 & 0.1 & -0.1 & 0.6 & 3.2 & 1.6 \\
\hline $100-499$ & 1.0 & -1.3 & -0.5 & -0.8 & 0.8 & 3.2 & 2.1 \\
\hline $500+$ & 0.1 & -1.3 & -2.0 & -2.9 & -0.2 & 2.3 & 2.2 \\
\hline TOTAL & 1.3 & -0.4 & -0.8 & 0.3 & 0.7 & 3.1 & 2.6 \\
\hline
\end{tabular}

6 The industrial distribution of employment is shifting towards sectors in which small firms are disproportionately represented, such as the consumer services. Even if the size distribution of employment within industries did not change, the aggregate share of employment in small firms would rise simply because of the changing distribution of employment among industries. A straightforward standardization (or decomposition) was performed to account for interindustry shifts by holding each industry share of employment at its 1978-79 level. The period 1978 to 1988 was used so that the end points would be in roughly the same position in the business cycle; we are interested in assessing the effect of the structural, not cyclical, change in the industrial distribution of employment. Firms were classified according to the average current size in 197879. The results of the standardization indicate that the changing composition of employment among industrial sectors accounted for about one-quarter of the difference in growth rates between small and large firms. Differences in job creation and loss within industries is significant and accounts for most (three quarters) of the total difference observed for the economy as a whole.

7 Which includes wholesale trade, transportation and communications, and is closely tied to the goods producing sector. 


\begin{tabular}{|c|c|c|c|c|c|c|c|}
\hline $\begin{array}{l}\text { FIRM } \\
\text { SIZE }\end{array}$ & $\begin{array}{l}\text { TOTAL } \\
\text { COMMERCIAL } \\
\text { ECONOMY }\end{array}$ & PRIMARY & MANUFACTURING & CONSTRUCTION & $\begin{array}{l}\text { DISTRIBUTIVE } \\
\text { SERVICES }\end{array}$ & $\begin{array}{l}\text { CONSUMER } \\
\text { SERVICES }\end{array}$ & $\begin{array}{l}\text { BUSINESS } \\
\text { SERVICES }\end{array}$ \\
\hline & \multicolumn{7}{|c|}{ DISTRIBUTION BY SIZE (\%) } \\
\hline $0-19$ & 24.0 & 16.1 & 9.0 & 48.2 & 19.3 & 34.8 & 24.0 \\
\hline $20-49$ & 11.9 & 8.5 & 9.4 & 18.1 & 11.3 & 14.3 & 10.0 \\
\hline $50-99$ & 8.3 & 5.9 & 8.9 & 9.4 & 7.9 & 8.7 & 7.2 \\
\hline $100-499$ & 16.0 & 16.0 & 22.0 & 15.2 & 15.1 & 12.3 & 15.2 \\
\hline $500+$ & 39.7 & 53.4 & 50.7 & 9.1 & 46.5 & 29.9 & 43.6 \\
\hline \multirow[t]{2}{*}{ TOTAL } & $100 \%$ & $100 \%$ & $100 \%$ & $100 \%$ & $100 \%$ & $100 \%$ & $100 \%$ \\
\hline & \multicolumn{7}{|c|}{$\begin{array}{l}\text { AVERAGE ANNUAL NET NUMBER OF JOBS CREATED BETWEEN CONSECUTIVE YEARS, } \\
\text { 1978-92, USING CURRENT AVERAGE SIZE (000s) }\end{array}$} \\
\hline $0-19$ & 63.4 & 1.0 & 6.0 & 3.7 & 7.2 & 33.7 & 11.7 \\
\hline $20-49$ & 16.3 & 0.2 & -0.1 & -0.3 & 1.2 & 12.1 & 3.2 \\
\hline $50-99$ & 9.2 & -0.1 & 0.2 & -0.1 & 0.7 & 6.9 & 1.5 \\
\hline $100-499$ & 12.2 & -0.5 & -2.2 & -0.6 & 1.6 & 10.0 & 4.0 \\
\hline $500+$ & 4.2 & -1.6 & -21.1 & -1.3 & -1.2 & 17.1 & 12.3 \\
\hline \multirow[t]{2}{*}{ TOTAL } & 105.3 & -1.0 & -17.2 & 1.5 & 9.5 & 79.8 & 32.6 \\
\hline & \multicolumn{7}{|c|}{$\begin{array}{l}\text { AVERAGE ANNUAL NET NUMBER OF JOBS CREATED BETWEEN CONSECUTIVE YEARS, } \\
\text { 1978-92, USING BASE YEAR SIZE (000s) }\end{array}$} \\
\hline $0-19$ & 156.5 & 4.0 & 21.1 & 14.0 & 20.6 & 67.0 & 29.8 \\
\hline $20-49$ & 1.6 & 0.0 & 1.3 & -2.6 & -0.8 & 3.0 & 0.7 \\
\hline $50-99$ & -5.3 & -0.4 & -1.4 & -1.4 & -1.7 & 0.2 & -0.6 \\
\hline $100-499$ & -10.6 & -0.8 & -6.4 & -3.7 & -1.7 & 4.8 & -2.7 \\
\hline $500+$ & -36.9 & -3.8 & -31.7 & -4.7 & -6.9 & 4.8 & 5.5 \\
\hline TOTAL & 105.3 & -1.0 & -17.2 & 1.5 & 9.5 & 79.8 & 32.6 \\
\hline
\end{tabular}

The story is slightly different in the services sector, as large firms did contribute to net employment growth, no matter which method of size in firms is used. Based on the current average size method, consumer services created 80,000 jobs per year on average over the period, of which about $20 \%$ was in large firms (with $30 \%$ of employment) and $42 \%$ in small firms (with $35 \%$ of employment). In the business services sector, about $38 \%$ of the employment increase was accounted for by larger firms (with $40 \%$ of employment) and $36 \%$ by smaller (with one quarter of the employment). Thus, net employment gains were found in both the large and small firms in these fast-growing industries. Large firms had higher rates of gross job gains in these industries than in the goods sector. Using the base year size method, small firms are more dominant in job creation (table 3). Nevertheless, it is in the goods and the distributive services sectors, which had slower overall growth in employment, in which small firms clearly dominate employment growth.

\section{Growth In Existing Small and Large Firms}

The results to this point cannot be interpreted as a reflection of growth in individual firms, particularly already existing small firms. It is the change in aggregate employment in the small (or large) firm sector that has been the focus. This is influenced by the incidence and size of births and deaths, and changes in continuing firms. A complete analysis of the importance of each of the components is beyond this paper, but the point can be made by referring to one particular group of firms, those that exist in a given year.

Employment growth in existing small firms will not necessarily outstrip that of existing large firms. As has been observed, job loss due to the disappearance or contraction of firms is greater among small than large firms. Thus, if one defines two cohorts of firms--all existing small and large firms at any given time--employment will tend to decline, or at least grow very slowly in 
both groups. This is because the birth process has been excluded, and it accounts for much of the expansion of employment in the small firm sector.

For example, consider the growth between 1981 and 1984 of firms which existed in 1981. Net employment growth among existing small firms is $-14 \%$ versus $-11 \%$ among the large. Much of the decline in small firms is due to firms disappearing; among the large firms, it is largely due to the decline in continuing firms. It is the new firms (excluded here) that result in the small firm sector displaying more rapid employment growth than the large; when the "newly identified" firms are added the growth rates become $+12 \%$ among small firms and $-9 \%$ among the large.

The results are similar between 1984 and 1988. Among firms which existed in 1984, employment rose $3 \%$ for small firms and was flat for large. When employment in "newly identified" firms over the period is added, the growth rates become $48 \%$ and $3 \%$. It is the fact that new firms tend to be small that makes much of the difference. This is important when considering policies which are oriented towards existing firms, or the creation of new firms.

A summary of the findings to this point is as follows:

1. There is one consistent finding. For both the entire Canadian commercial economy and the manufacturing sector, the growth rate of (net) employment decreases monotonically as size of firm increases, no matter which method of sizing firm is used. The small firm sector has accounted for a disproportionate share of both gross job gains and job losses, and in the aggregate, accounted for a disproportionate share of employment increase over the 197892 period. This is observed for all methods of determining firm size, whether using short run (year to year) or longer run (over three or more years) job gains and losses. It is also observed during a period of recession and recovery (1981-84), and expansion (1984-88).

2. This is unlike the results in the U.S. manufacturing sector where adjustments for measurement issues resulted in small and large plants playing an equal rate in net job creation. In Canada, the disproportionate role of small firms is particularly evident in the goods-producing and distributive services sectors, where employment growth has been the slowest. In the faster growing consumer and business services sectors, the differences in employment growth between small and large firms is less, but it is still evident.

3. But the method of sizing firms does have a significant impact on the findings. Compared to the traditional method of sizing used in most previous studies, the methods proposed by Davis et al (1993) decrease the observed gross job gain and increase the gross job loss in small firms. They do the opposite for large firms. Thus, the dominance of small firms in net job creation is reduced, but not eliminated, by these measures as compared to earlier findings.

4. These results reflect the combined effects of births, deaths, and expansion and contraction of continuing firms. For firms that exist at any given time, the results suggest that employment in existing small firms is likely to expand at roughly the same rate as that in existing large firms. To some considerable degree, it is the fact that most new firms are concentrated in the small firm sector that results in its higher overall rate of gross job gain and net employment gain. 


\section{The Changing Size Distribution of Employment in Canada}

Job gain, loss and net employment growth have been greater in the small than large company sector. Another more direct measure of the changing significance of small and medium sized companies or establishments is the changing distribution of employment by size. The relationship between job gain and loss by size and the cross-sectional distribution of employment by size is not obvious. The more rapid growth observed among small firms on average may mean that the share of employment in the small firm sector would increase if most firms experiencing such growth nonetheless remained small. It may also be the case that as some small firms grew and became medium sized firms, the share of employment in that sector would increase. The effect on the cross-sectional distribution would depend on the dynamics of the growth process.

Regardless of the nature of this process, the changing distribution of employment (or payroll) by size is a direct indicator of the changing significance of small and large firms in the Canadian economy.

For the economy as a whole, we have consistent data only over the 1983 to 1991 period $^{8}$. The share of employment in large (over 500 employees) firms did decline significantly over that period, from $40.1 \%$ in 1983 to $36.4 \%$ in 1991 (table 4). The offsetting increase was observed mainly in small-to mid-sized firms, as the share of employment in firms with under 100 employees rose from $44.8 \%$ in 1983 to $47.8 \%$ in 1991 . The share of employment in very small firms (under 20 employees) displayed only a small increase over the period, from $25.0 \%$ to $26.1 \%$. Similar changes in the distributions are observed within the major industrial sectors (not reported here) indicating that this is not just a result of the changing industrial structure of employment.

Baldwin and Picot, (1995), looking at the changing distribution of employment in establishments by size in manufacturing found more significant changes through the 1980s in particular. The share of employment in manufacturing plants under 100 employees rose from around 30\% in 1980 to almost $37 \%$ by 1989 . Thus, the significance of small and medium size plants and companies did increase in the Canadian economy over the 1980s, at least as measured by the share of employment in those sectors. The next section asks whether similar changes are observed regarding the distribution of payroll.

\section{Controlling for Relative Changes in Wages and Hours Worked in Small and Large Companies}

Job quality is an issue when discussing job creation in small and large firms. Various aspects of differences in quality have been well documented in Canada and elsewhere, including an overview by Brown, Hamilton and Medoff (1990). In Canada, Morissette (1993) showed that during 1986, compared to small firms, an hour worked in a large firm was 5 times more likely to be unionized, and 5 times more likely to be covered by a pension plan. His work also demonstrated that even after controlling for wage and benefit advantages in large firms, tenure with the firm was 11 months longer in large than small firms. And Picot (1992) noted that after controlling for

8 The method of determining employment levels in firms of different sizes was altered in 1983, rendering a break in the time-series. 
differences in observable characteristics and industry, a worker in a small Canadian firm was twice as likely to be permanently laid off in any given year as one in a large firm. And regarding wage differentials, Morissette showed that in the aggregate, large firms paid an hourly wage in full-time jobs that was 50\% higher than among small firms. After controlling for small observable differences and unobservable fixed abilities, however, this was reduced to $10 \%$.

Such differences in quality are not typically considered in the types of job creation studies reviewed above. If the differences in quality are constant through time, this is not an issue. If, however, the relative wages or hours worked between small and large firms are changing, this can influence the results.

Most earlier studies, including the results in the first part of this paper, have used employment as their unit of analysis. The measure is a form of average annual employment ${ }^{9}$ which does not explicitly measure hours worked; it is an average annual headcount. This means, for example, that part-time is not distinguished from full-time employment. But it is well known that part-time employment has been increasing as a share of total employment over the past two decades. This increase may be more noticeable in the small than large firm sectors because of differences in hiring practices in these companies, or because of sectoral differences. Much of the increase in part-time employment has been in the consumer services sector, where small companies are disproportionately represented.

It is possible that some of the more rapid increase in job creation observed among small firms is simply a reflection of more rapidly increasing part-time employment in that sector (relative to the large firm sector). If an hours based measure of employment were used, some of the differential may disappear.

There is a second issue. If the wage gap between small and large firms is increasing, the more rapid employment growth in small firms noted earlier may not be producing comparable gains in the wages paid to employees. There is mixed evidence on this in Canada. In the manufacturing sector, Wannell (1991) found that annual earnings in small, relative to large, firms fell from .73 in 1980 to .64 by 1986 . Baldwin (1995), studying manufacturing plants in Ontario, found that the relative wages paid in small (under 20 employees) plants fell from .84 of the average for all plants in 1971 to .70 in the late 1980s. A decline was also noted in the 20 to 99 class. The relative wages in plants with over 1000 employees rose from 1.2 to 1.34 however.

In the services sector, however, Wannell observed that the wage gap between small and large firms narrowed between 1983 and 1988. Thus, there does not appear to be a consistent trend across the economy as a whole.

We ask whether accounting for changes in the relative (between small and large firms) wages paid or hours worked over the period significantly influences the results. In essence, we are introducing one aspect of job quality into the determination of employment growth. Since hours

9 In the LEAP longitudinal file of companies, the employment measure is referred to as an Average Labour Unit (ALU), which is, because of the manner in which it is derived from the payroll of companies, conceptually similar to the employment count used in the Survey of Employment, Payroll and Hours (SEPH) in Canada. This is an average annual employment count where one cannot distinguish between full-time and part-time. 
worked and hourly wages paid are not on the LEAP data source being used, we turn to payroll as the unit of measurement.

Payroll is jointly determined by hours worked and wages paid. Any relative change between companies of different sizes in either of these components would be reflected in a change in the relative growth rate of payroll. It is not possible, however, to separate the relative movements in one of the variables from that of the other. Payroll is deflated using the CPI, since it is the purchasing power of workers in which we are interested. Size of firm is established using the employment measures described earlier, but firms are classified as expanding or contracting based on the change in their (deflated) payroll. The question being asked is then "Have small firms accounted for a disproportionate share of the growth in payroll over the past decade and onehalf?"

The share of payroll accounted for by large firms exceeds their share of employment, for the reasons noted earlier. In 1991, small firms accounted for $26 \%$ of employment, but only $21 \%$ of payroll. Large firms (over 500) on the other hand accounted for $36 \%$ of employment, and $43 \%$ of payroll (table 4). However, the relative values of the employment and payroll distributions changed little over the 1980s. As with the employment distribution, the share of payroll in small and medium sized firms increased slightly over the 1980, that in large firms decreased.

\begin{tabular}{|c|c|c|c|c|}
\hline YEAR & 0-19 & 20-99 & 100-499 & $500+$ \\
\hline & \multicolumn{4}{|c|}{ A. DISTRIBUTION OF EMPLOYMENT (ALU'S) } \\
\hline 1983 & 25.0 & 19.8 & 15.2 & 40.1 \\
\hline 1986 & 25.0 & 21.0 & 16.0 & 38.1 \\
\hline 1988 & 24.7 & 21.8 & 17.0 & 36.7 \\
\hline \multirow[t]{2}{*}{1991} & 26.1 & 21.7 & 15.8 & 36.4 \\
\hline & \multicolumn{4}{|c|}{ B. DISTRIBUTION OF PAYROLL } \\
\hline 1983 & 18.9 & 17.4 & 15.9 & 47.7 \\
\hline & $(.76)$ & $(.88)$ & $(1.05)$ & $(1.19)$ \\
\hline \multirow[t]{2}{*}{1986} & 19.4 & 18.6 & 16.5 & 45.5 \\
\hline & $(.78)$ & $(.89)$ & $(1.03)$ & $(1.19)$ \\
\hline \multirow[t]{2}{*}{1988} & 19.3 & 19.8 & 17.7 & 43.2 \\
\hline & $(.78)$ & $(.91)$ & $(1.04)$ & (1.18) \\
\hline \multirow[t]{2}{*}{1991} & 21.0 & 19.4 & 16.4 & 43.2 \\
\hline & $(.80)$ & (.89) & (1.04) & $(1.19)$ \\
\hline
\end{tabular}

Turning to growth (and decline) in payroll, again small firms play a disproportionate role as they did with employment. The payroll gain and loss rates, and the net change in payroll are very similar to the job gain and loss rates, and the net employment change (table 5). The net increase in payroll in small firms are marginally lower than that of employment, while among large firms the opposite is true, suggesting minor relative changes, but the differences overall is not large. For the commercial economy as a whole, these data suggest that the effects of changes in relative job quality (between small and large firms) as measured by the joint effect of hours and wages had little influence on the earlier reported results. Of course, the differences in job quality between small and large firms persists, and this observation may be somewhat different for different sectors of the economy. In particular, the earlier work reported suggests that there may have been significant changes in relative job quality in the manufacturing sector in Canada. 
Baldwin (1995), in studying manufacturing plants in Ontario, finds that taking into account relative wage changes between small and large firms (an increasing wage gap in manufacturing) does alter some of the earlier conclusions for that sector. The annual rate of job change in smaller plants is reduced, although it is still greater than in the large firm sector. When employment is weighted by wages paid, large plants are seen in many cases to produce net employment gains, not always net employment losses as in the earlier reported work. Thus, generally speaking smaller plants in manufacturing continue to be important sources of job creation (after adjusting for quality as measured by wages), but their influence is reduced. 


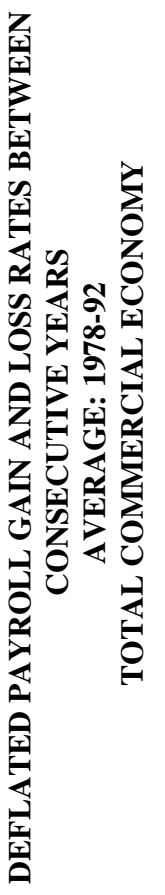

年是
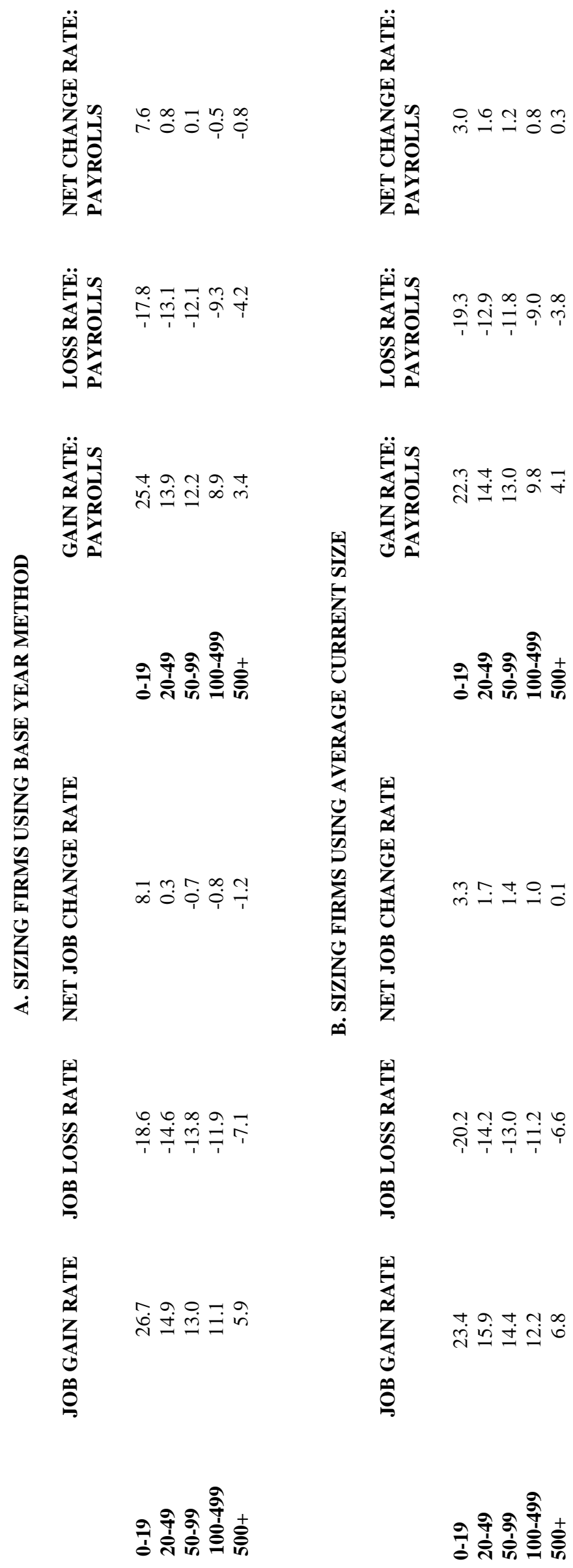


\section{Part II: The Concentration of Growth in the Smal and Large Firm Sectors}

The previous results are based on the average performance of firms in different size classes, (e.g. average net employment growth among all small firms, including births and continuing firms). Thus, they refer to some "typical" company. But of course few companies register typical employment growth, and the previous results tell us nothing about the distribution of the growth among business units; the extent to which some firms are growing faster than others within, say the small firm sector. If the growth is highly concentrated, knowing that a firm is small may provide little information about its prospects for growth, since with a great deal of concentration of growth, most small firms grow relatively little or decline, a few expand a lot.

And having identified the fast growing (continuing) firms during any given period, what does that tell us about their future prospects for growth? Do firms which are observed to have rapid employment growth in one period repeat that performance in the subsequent? Or is the growth process more random, with a high degree of concentration during any given period, but little correlation between the rapid growers in two different periods? We address this issue in this section.

Job gain and loss appears to be quite highly concentrated among a relatively few firms. Davis and Haltiwanger (1993) found that in the U.S. manufacturing sector two-thirds of job gains and losses are concentrated in manufacturing plants that expand or contract by $25 \%$ or more within a oneyear period. Blanchflower and Burgess (1994) found job creation (and destruction) to be highly concentrated among very few firms in the UK. Among expanding plants they found that in any given year, $50 \%$ of the job creation was accounted for by $10 \%$ of expanding plants. They found virtually the same degree of concentration of job loss; $50 \%$ was associated with only $10 \%$ of declining plants.

These results do not distinguish between small and large firms, something of importance here. Blanchflower and Burgess (1994) find that large firms are disproportionately represented in the firms accounting for most job growth, simply because of their size. But the concentration is not explained by this observation.

Here we look at concentration within size classes, since the focus of the paper is on size class differentials. The data are from LEAP, and they cover all companies in the commercial economy for the period $1983 / 84$ to $1988 / 89^{10}$. As in the earlier work reported above, one can think of both short-run or long-run employment change at the company level; we observe the degree of concentration in both. Most studies base their concentration results on employment change in a single year (short-run), and we wish to be consistent with these. However, much of that employment change may be transitory, as noted earlier. We also wish to observe the degree of concentration of longer run change in employment. Over a longer period (say three years), the transient component will be reduced, and the longer run component of employment change increased as compared to single year change.

10 This period is used because of data constraints. In the LEAP file the manner in which payroll is converted to employment has been revised back to 1983/84, and we wished to make use of these revisions. We do not go beyond 1988/89 because of a break in the longitudinal LEAP file at that time (see appendix). 


\section{The Concentration of Short-Run Employment Gains and Losses}

\section{The Approach}

We start by looking at the concentration of job gain and loss between consecutive years, in this case between the four consecutive sets of years between 1984-85 and 1987-88. We calculate job gain and loss as earlier in the paper, and size firms using two methods, base year (size in year t) and average current size (i.e. the average over years $t$ and $t+1$ ). The results indicate that the degree of concentration is very similar for these two methods, and hence we only report the results for the second. Employment change is that calculated between years $t$ and $t+1$. Firms are separated into growing and declining, and within each group firms are rank ordered (within size groups) according to the volume of gross job gain (or gross job loss) ${ }^{11}$. Quintiles are established within each size group and for growing and declining firms separately. This is done using employment weighted firm counts. For example, among growing small firms between any two years, the top quintile would consist of those small firms that registered the largest increase in employment and collectively accounted for $20 \%$ of employment among expanding firms. The top quintile among decliners would contain those small firms which collectively accounted for $20 \%$ of employment among declining firms, and were the largest job losers (among firms with under 20 employees) between the two years. This work focuses on continuing firms only. Births and deaths are excluded from this analysis. We are concerned with the degree of concentration of employment growth among firms that existed at both the beginning and end of the period.

In order to minimize the impact of potentially erroneous outliers (companies with extremely large growth or decline rates) on the results, we exclude all companies in which employment increases by a factor of four between consecutive years, or a factor of six over a three year period. Similarly, we exclude all companies in which employment falls to 1/4th of its previous value over two years, or $1 / 6$ th over three years. This process excludes the cases in which a potentially improper company match may have been made between years, resulting in dramatic employment changes. Such outliers may be important here because they are concentrated in the top quintile (of job gain or loss) and can potentially influence the results. The selection of the cut-off points, while arbitrary, was based on a visual inspection of the distribution of employment growth (or decline $)^{12}$.

11 There is the issue of whether to rank order firms by volume or rate of job gain (or loss). Since we are interested in which firms account for the most job gain or loss, we chose volume. Also, calculating growth rates for very small firms (1 or 2 employees) can be misleading.

12 In doing this, we exclude companies that account for $7 \%$ of employment. It is unlikely that all of this employment is due to improper outliers, as it is concentrated among small firms. If there is a bias introduced by this procedure, it is probably towards underestimating concentration in the small relative to large firm sectors. Some very small companies (of 1 or 2 employees) may have truly grown by a factor of 4 , (to 4 or 8 employees) in a single year. These companies would be excluded. This is a fairly conservative approach which will if anything tend to underestimate the degree of concentration among small firms in particular. However, it seems less likely that a company of 500 or 1000 would grow to 2000 or 4000 in a single year without involving a merger or some similar restructuring. We also exclude continuers that were born in the base year of the calculation, since it is not clear whether the growth following the first (perhaps partial) year of existence should be allocated to births (which we have excluded) or continuers. 
A second methodological test was carried out to ensure that the concentration results were not significantly influenced by mergers or other changes in company structure. As a test, we restricted the analysis to those firms for which mergers or changes in company structure over the period seemed unlikely. This was done by selecting companies which maintained the same set of Revenue Canada payroll deduction accounts over the entire period. If part or all of a company is bought or sold, the company is required to open a new payroll deduction account with Revenue Canada $^{13}$. The results for this sub-sample of firms were very similar to that for the entire population of companies, suggesting that changes in company structure and their potential impact on employment do not account for the majority of the results.

\section{Concentration of Short-Term Employment Change}

We start with the small firm sector. Both job loss and job gain are highly concentrated among relatively few small firms. Among expanding firms, those with the largest job gain (i.e. those in the top quintile) accounted for $20 \%$ of employment, but $43 \%$ of gross job creation (table 6). Only $9.5 \%$ of all expanding small firms were in this quintile ${ }^{14}$. And since these represent only expanding firms, for the small firm sector as a whole (including expanding and declining firms), $43 \%$ of gross job gain was accounted for by only $5.0 \%$ of companies. These small companies not only accounted for the highest volume of job gain, they also tended to have higher rates of job growth. The gross job gain rate was $64 \%$ in the top quintile of expanding firms, only $7 \%$ in the bottom quintile.

The story is similar among declining firms. Those firms with the largest job losses accounting for $20 \%$ of employment in the base year registered $38 \%$ of job loss (table 6). This represented only $6.8 \%$ of declining firms. Thus, $3.1 \%$ of all small firms (expanding and declining) accounted for $38 \%$ of year to year job loss, and $5.0 \%$ accounted for $43 \%$ of year to year job gain. This suggests tremendous variation among small firms in terms of job creation performance.

Among mid-sized companies the concentration is slightly greater. The roughly $10 \%$ of all mid sized firms (employment of 20 to 500) that were the top performers in terms of job creation accounted for around $50 \%$ of job gain. Large firms (over 500), display considerably less concentration. The top performing large firms accounted for $12 \%$ of all employment $(20 \%$ of employment in expanding firms), and $32 \%$ of gross job gain. This was achieved by only $3 \%$ of the very largest companies, however. The difference between the top two quintiles is not great in the large firm sector, indicating less concentration (charts 4 and 5).

13 Thus, no change in the PD accounts held by a company suggests no mergers or sell-offs. This is the account used by companies to remit taxes payable by companies for the employee to Revenue Canada.

14 Since firms were rank ordered by volume (rather than rate) of job creation, the larger firms are more likely to be in the top quintile. For example, in the small firm sector the average size in the bottom quintile (those with the lowest volume of job creation) was 2.1 workers per firm; in the top quintile it was 8.7. With an identical growth rate, a larger firm would be in a higher quintile than a smaller firm. Thus, the top quintile represents $20 \%$ of employment, but a much smaller percentage of firms. But this tendency for large firms to be in the higher quintile does not account for all the difference among quintiles. If it did, the employment growth rates in the quintiles would not be monotonically increasing from bottom to top. Although rank ordered according to volume of job gain (or loss), the result is that those firms accounting for the largest volume of gain (or loss) also had the highest rates of growth (or) decline. The average gross job gain rate in the top quintile was $64 \%$, in the lowest $7 \%$. 
TABLE 6: THE CONCENTRATION OF JOB GAIN AND JOB LOSS, BY FIRM SIZE, ANNUAL AVERAGE 1984/85 TO 1987/88, CONTINUING FIRMS

EXPANDING FIRMS

QUINTILE

0-19

\section{$\%$ OF EMPLOYMENT}

$\%$ OF COMPANIES

$\%$ OF JOB GAIN (LOSS)

JOB GAIN (LOSS) RATE

20-99

$\%$ OF EMPLOYMENT

$\%$ OF COMPANIES

\% OF JOB GAIN (LOSS)

JOB GAIN (LOSS) RATE

100-499

$\begin{array}{llllll}\text { \% OF EMPLOYMENT } & 20.0 & 20.0 & 20.0 & 20.0 & 20.0\end{array}$

$\begin{array}{llllll}\text { \% OF COMPANIES } & 20.8 & 21.0 & 20.3 & 19.6 & 18.4\end{array}$

$\begin{array}{lrrrrr}\text { \% OF JOB GAIN (LOSS) } \quad 2.6 & 8.0 & 14.0 & 23.2 & 52.2\end{array}$

JOB GAIN (LOSS) RATE

$500+$

$\begin{array}{llllll}\text { \% OF EMPLOYMENT } & 19.9 & 19.8 & 19.7 & 19.9 & 20.8\end{array}$

$\begin{array}{llllrr}\text { \% OF COMPANIES } & 37.7 & 31.1 & 17.9 & 9.9 & 3.3\end{array}$

$\begin{array}{llllll}\text { \% OF JOB GAIN (LOSS) } & 5.3 & 15.1 & 20.1 & 27.2 & 32.3\end{array}$
DECLINING FIRMS

QUINTILE

\begin{tabular}{rrrrr}
\multicolumn{1}{c}{$\mathbf{1}$} & \multicolumn{1}{c}{$\mathbf{2}$} & \multicolumn{1}{c}{$\mathbf{4}$} & \multicolumn{1}{c}{} \\
& & & & \\
20.0 & 20.0 & 20.0 & 20.0 & 20.0 \\
43.3 & 23.5 & 15.8 & 10.7 & 6.8 \\
6.1 & 13.3 & 18.7 & 24.3 & 37.6 \\
-6.4 & -13.8 & -19.5 & -25.3 & -39.2 \\
& & & & \\
& & & & \\
20.0 & 20.0 & 20.0 & 20.0 & 20.0 \\
25.5 & 23.6 & 20.7 & 17.6 & 12.6 \\
3.2 & 9.8 & 16.7 & 25.8 & 44.4 \\
-3.0 & -8.9 & -15.2 & -23.5 & -40.3 \\
& & & & \\
& & & & \\
20.0 & 20.0 & 20.0 & 20.0 & 20.0 \\
23.9 & 22.8 & 20.7 & 18.7 & 13.9 \\
2.6 & 8.5 & 15.0 & 25.2 & 48.7 \\
-2.0 & -6.4 & -11.3 & -19.1 & -36.9 \\
& & & & \\
20.1 & 21.3 & 18.8 & 20.4 & 19.4 \\
44.1 & 29.4 & 14.8 & 8.7 & 3.0 \\
5.3 & 14.7 & 19.0 & 27.2 & 33.8 \\
-2.5 & -6.6 & -9.6 & -12.7 & -16.6
\end{tabular}

TABLE 7: THE CONCENTRATION OF JOB GAIN AND JOB LOSS, BY FIRM SIZE, OVER THE PERIOD 1983 TO 1986 , CONTINUING FIRMS

EXPANDING FIRMS

QUINTILE

$\begin{array}{lrrrrr}\text { 0-19 } & & & & & \\ \text { \% OF EMPLOYMENT } & 20.0 & 20.0 & 20.0 & 20.0 & 20.0 \\ \text { \% OF COMPANIES } & 39.5 & 23.7 & 16.6 & 11.8 & 8.5 \\ \text { \% OF JOB GAIN (LOSS) } & 4.9 & 11.6 & 17.1 & 23.4 & 42.9 \\ \text { JOB GAIN (LOSS) RATE } & 14.9 & 35.5 & 52.5 & 71.8 & 131.4 \\ & & & & & \\ \text { 20-99 } & & & & & \\ \text { \% OF EMPLOYMENT } & 20.0 & 20.0 & 20.0 & 20.0 & 20.0 \\ \text { \% OF COMPANIES } & 22.6 & 21.9 & 20.6 & 18.8 & 16.2 \\ \text { \% OF JOB GAIN (LOSS) } & 2.7 & 8.3 & 14.8 & 23.9 & 50.2 \\ \text { JOB GAIN (LOSS) RATE } & 6.4 & 19.5 & 34.7 & 56.0 & 117.5 \\ & & & & & \\ \text { 100-499 } & & & & & \\ \text { \% OF EMPLOYMENT } & 20.0 & 20.0 & 20.0 & 20.0 & 20.0 \\ \text { \% OF COMPANIES } & 21.9 & 21.4 & 21.0 & 19.6 & 16.1 \\ \text { \% OF JOB GAIN (LOSS) } & 2.7 & 7.9 & 14.4 & 23.3 & 51.7 \\ \text { JOB GAIN (LOSS) RATE } & 5.0 & 14.7 & 26.9 & 43.5 & 96.5 \\ & & & & & \\ \text { 500+ } & & & & & 2.7 \\ \text { \% OF EMPLOYMENT } & 19.9 & 20.0 & 20.1 & 18.7 & 21.3 \\ \text { \% OF COMPANIES } & 35.0 & 31.9 & 21.6 & 8.7 & 2.8 \\ \text { \% OF JOB GAIN (LOSS) } & 4.8 & 15.0 & 24.5 & 26.1 & 29.6 \\ \text { JOB GAIN (LOSS) RATE } & 5.1 & 16.1 & 26.0 & 29.9 & 29.8\end{array}$

DECLINE FIRMS

\section{QUINTILE}

\begin{tabular}{rrrrr}
\multicolumn{1}{c}{$\mathbf{1}$} & \multicolumn{1}{c}{$\mathbf{3}$} & $\mathbf{4}$ & \multicolumn{1}{c}{$\mathbf{5}$} \\
& & & & \\
20.0 & 20.0 & 20.0 & 20.0 & 20.0 \\
45.0 & 23.3 & 15.1 & 10.2 & 6.4 \\
7.1 & 14.5 & 19.5 & 24.6 & 34.3 \\
-11.0 & -22.6 & -30.4 & -38.4 & -53.4 \\
& & & & \\
& & & & \\
20.0 & 20.0 & 20.0 & 20.0 & 20.0 \\
24.9 & 23.1 & 21.6 & 18.2 & 12.2 \\
3.5 & 10.3 & 18.6 & 27.8 & 39.9 \\
-4.7 & -14.0 & -25.3 & -37.9 & -54.5 \\
& & & & \\
& & & & \\
20.0 & 20.0 & 20.0 & 20.1 & 19.9 \\
23.7 & 21.8 & 21.3 & 19.7 & 13.6 \\
3.0 & 8.6 & 16.4 & 28.2 & 43.9 \\
-3.5 & -10.1 & -19.5 & -33.3 & -52.5 \\
& & & & \\
20.1 & 20.3 & 21.9 & 18.0 & 19.8 \\
41.2 & 28.9 & 20.3 & 6.4 & 3.2 \\
6.3 & 17.0 & 27.4 & 19.9 & 29.3 \\
-4.9 & -13.3 & -19.8 & -17.5 & -23.4
\end{tabular}


Thus, short-run employment expansion (and decline) is quite concentrated, and much more in the small and medium than the large firm sector. And not surprisingly, given earlier results in this paper, growth rates of the top performing small firm are much greater than for the large.

These results demonstrate the shortcoming of dwelling only on "average" results of the kind reported earlier when considering policy implications. It is true that the small firm sector accounts for a disproportionate share of both gross job gain, gross job loss and net employment growth. But the concentration results clearly show that when thinking about individual firms, this result alone is not sufficient information. If one were attempting to target policies to the group of fastgrowing firms, which is implicit in policies oriented to small firms, it is necessary to realize that there is such a set of companies among all size classes, not just among small firms. The determinants of growth include many factors other than size.

We have dwelt on the concentration of short-run (year to year) employment change to this point. But as noted earlier, the transitory component of change will be greater among short-run than long-run change. Thus, in order to determine the concentration of longer run employment growth among firms, we turn to employment change over a three year period, 1983 to 1986. Most analysts would likely be interested in knowing which firms register longer-run job gains (or losses), and the extent of the concentration of such growth (or decline).

\section{The Concentration of Longer-Run Job Gain and Loss Among Continuing Firms}

The degree of concentration of longer-run job gain and loss among continuing firms is very similar to that for short-run change. The concentration of both growth and decline is substantial in the small firm sector (5\% of small continuing companies accounted for $43 \%$ job gain, $3 \%$ accounted for $34 \%$ of job loss) (table 7). Concentration was somewhat greater among mid-sized firms, and substantially less among large companies. In fact, when weighting firms by their employment, there was little concentration among large firms in employment gain or loss. The large companies with the largest job gains (and 20\% of employment in expanding firms) accounted for only $30 \%$ of gross job gain, not much different than the next two quintiles which accounted for $26 \%$ and $25 \%$ of job gain respectively. Job gain (or loss) is not as highly as concentrated in other size groups $^{15}$.

The concentration among all size classes is compared in chart 4, where each quintile's share of total (in all size classes) job gain/loss is presented. The highest performing small firms (in the top quintile of small job gainers) accounted for about $15 \%$ of total job gain, whereas the highest performing large firms (in the top quintile of large job gainers) accounted for less than 7\%. High performing small firms out-perform high performing large firms in job creation. However, most small firms were not in the high-performing category...almost half lost jobs, not gained them

15 However, because these firms are very large, most job gain is accounted for by relatively few large firms. Considering job growth, the top two quintiles account for $46 \%$ of job gain, and this is among only $6 \%$ of all large firms. A similar story holds for job loss. Thus, a few large firms account for most job gain and loss, but this is largely due to the fact that they are simply much larger than other large firms. When this is accounted for (by weighting firms by their employment), much of the concentration of job gain and loss in the large firm sector disappears. 


\section{CHART 4: SHARE OF TOTAL JOB GAIN/LOSS}

\section{3-86}

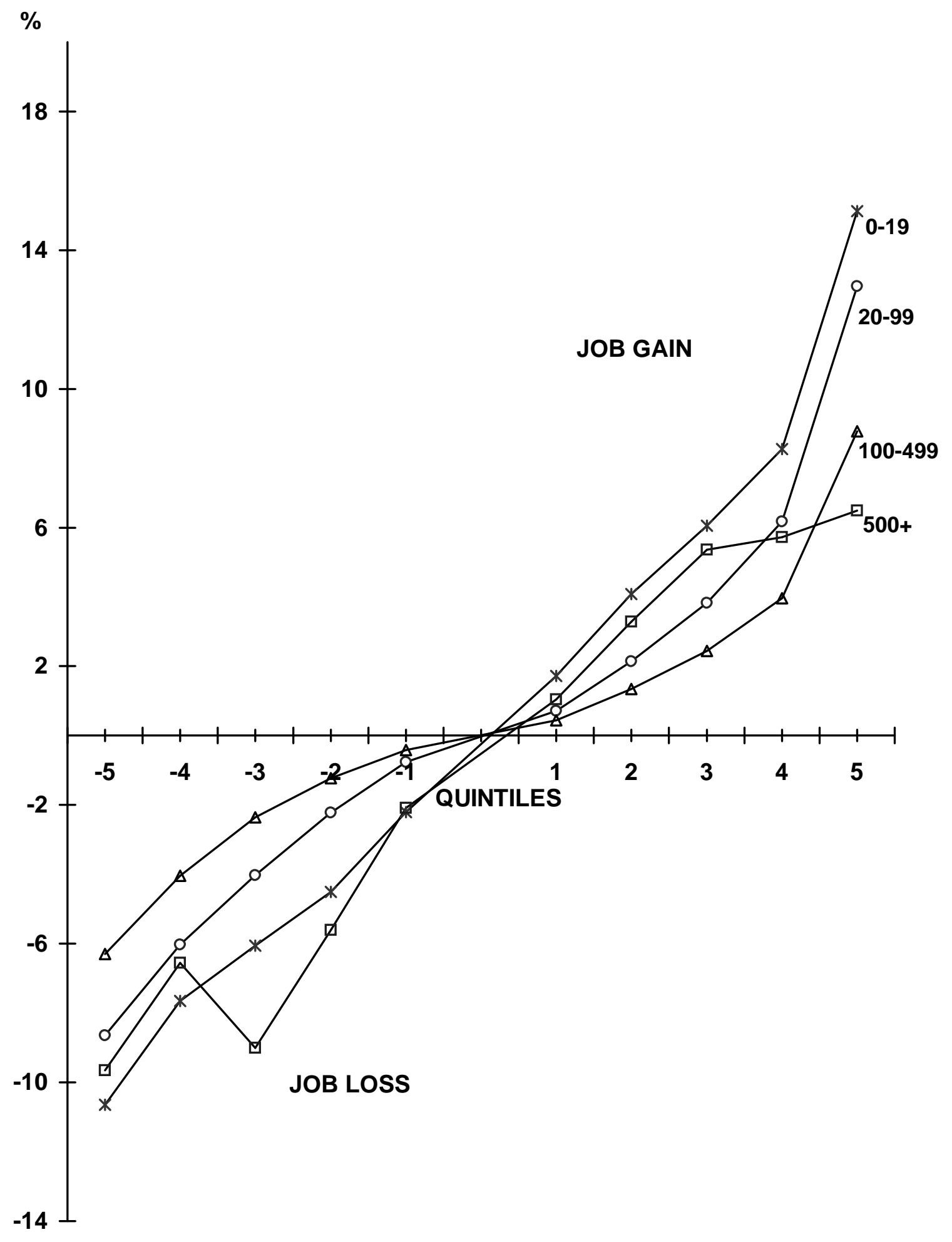


(table 5) and among the gainers many accounted for little job gain. Thus, the large (500+) firms in the top three quintiles of growing firms out-performed roughly $70 \%$ of all small firms in terms of volume of job creation. Each of the top three quintiles (those with the largest job creation) for large firms accounted for $6 \%$ of total job creation. This is higher than the results for the bottom $70 \%$ of small firms, as they either lost jobs, or gained relatively few (chart 4). Knowing size only tells little about the job creation potential of an individual firm. Some large firms create many jobs, many small firms shrink in size.

Long run employment growth rates are also dramatically different among size classes (chart 5, table 7); the top performing small firms had an average growth rate of $131 \%$ over the period, and this declined monotonically to $29 \%$ among the top performing large firms. In particular, the firms with the very rapid job growth rates are concentrated in the small and medium size sector. The fastest growing firms in the 0-499 size averaged growth rates of $90 \%$ to $131 \%$ over the three years, compared to $29 \%$ among the fastest growing large (500+) firms (chart 5).

These results remind us of a couple of points. First, knowing only the size of a company provides very limited information on its growth prospects. While it is true that on average net growth is greater in the small firm sector, the difference between the rapid job creators and the largest job losers in the small firm sector is substantial. The top performing small firms more than doubled (increasing $131 \%$ ) over the $1983-86$ period, and created $43 \%$ of all jobs in that sector (15\% of jobs overall). However, the poorest performing small firms (that did not disappear, as many small firms would have over the period) fell by about $1 / 2$ in size, and lost $34 \%$ of all jobs lost by small firms (11\% of all jobs lost overall). The same kind of story holds in other sectors, but much less so in the large firm sector. The variation among firms in terms of job creation performance is much less in that sector.

Second, while both job gain and loss is concentrated in the small firm sector, it is found among all sizes of firms. Over the 1983-86 period, the large firms in the top three growth quintiles grew at around $25 \%$, and created 230,000 jobs. These best performing large firms are not a trivial component of the large firm sector, as they account for about $30 \%$ of large firm employment. And their performance was superior to that of the majority of the small firm sector. Small firms which together accounted for $70 \%$ of small firm employment did worse over the period than these large firms, as most of them lost jobs. While one can argue it is unreasonable to compare the best performing large firms to the poorest performing small firms, this is done simply to make the point that there is a lot of variation in growth patterns, and to think only in terms of the averages presented earlier is to consider only part of the picture.

\section{Future Prospects for the Top Performing Companies}

What does this information concerning the employment growth pattern over one period, in this case three years, tell us about the future? Do firms that grow over one period continue to grow in the future. As noted earlier, it has been demonstrated in earlier work that much of the employment change at the firm level is transitory, and that regression to the mean is a significant phenomenon in the dynamics of firm employment growth. Employment gains in a plant or company in one year may be reversed in the following year. Thus, short run gains in employment may not be correlated with longer run gains. For that reason we turn to employment change over the three 
CHART 5: JOB GAIN AND LOSS RATES BY QUINTILES, 1983-86

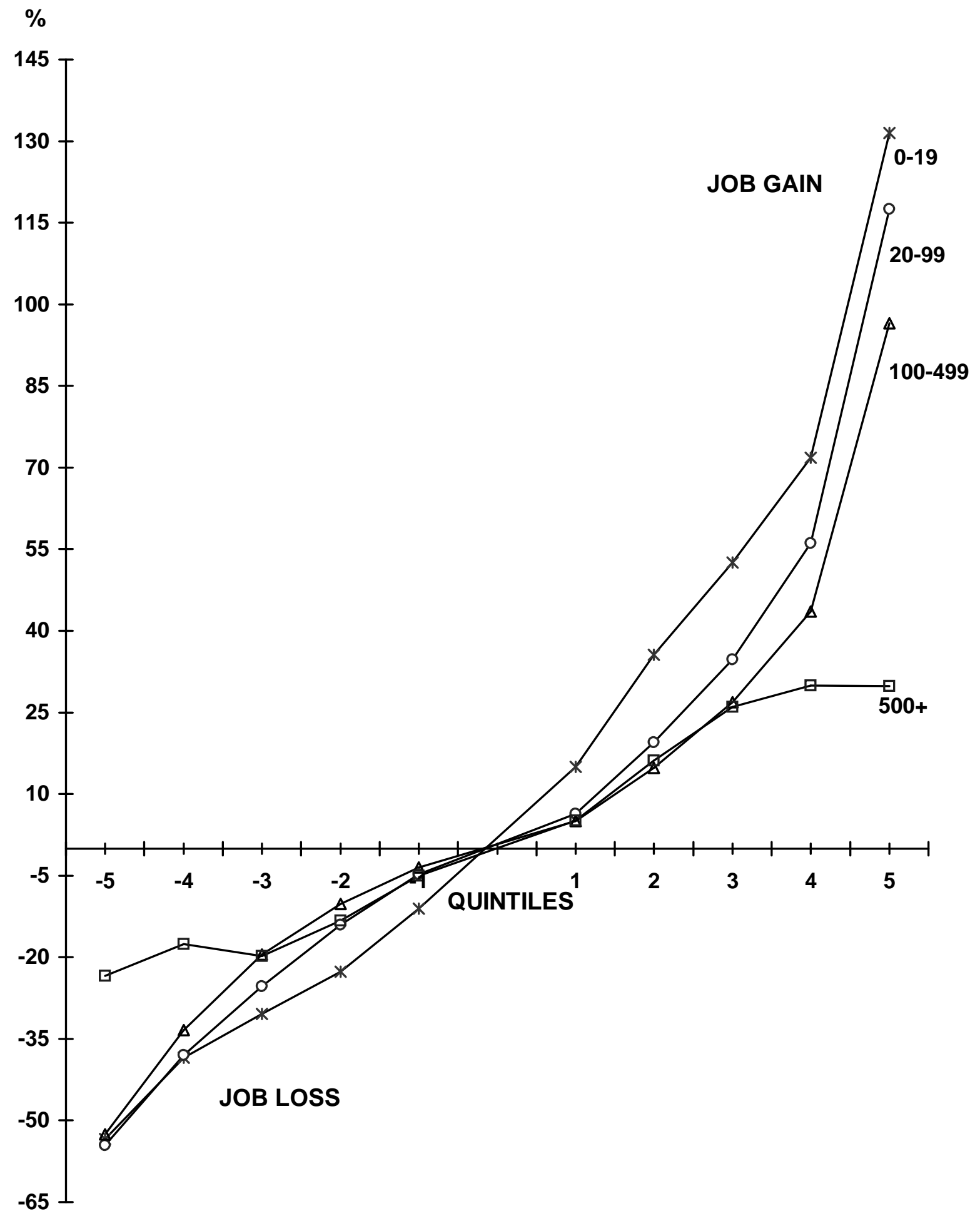


year period (1983 to 1986), and ask if these somewhat longer term gains are repeated in the future, in this case over the subsequent three year, 1986 to $1989^{16}$.

Only continuing firms are included in the analysis. They are classified by quintile (expanding and contracting separately) based on the volume of job gain (or loss) during the 1983-86 period as before. The growth rates are then calculated for the 1983-86 and the 1986-89 periods for each quintile by size class. The same firms are included in each size class/quintile combination in the two periods. Deaths are allowed in the second period, since the objective is to determine how firms which survived the first period do during the second, which includes the possibility of disappearing. Because deaths are included in the second, but not the first period, the overall growth rates are very different. For example, employment in small continuing firms grew 18.6\% during the first period, only $2.6 \%$ during the second.

The results are shown in table 8 . There appears to be little correlation between the growth in the first period, and that in the second. Thus, the firms which created the most jobs in each size class (i.e. those in the 5th quintile of expanding firms) did not behave much differently than most other firms during the second period. For example, in the small firm sector these rapid job creators grew almost seven times as fast as other small firms over 1983-86, but during 1986-89 they grew not quite twice as fast. The same is true in the other size classes. Among the medium and large size sectors, companies in the top quintile which grew from 7 to 10 times faster than their counterparts in the same size class during the first period displayed average growth in the second. And the same is more or less true among the greatest job losers (that survived the first period). Firms with the largest losses during the first period exhibited growth that was often below average during the second.

Expressing growth as the natural log of the employment change (i.e. $\ell n(E 86 / E 83)$ ), these same results are shown in chart 6. Among small firms (chart 6A), growth during 1983-86 ranges from +.80 among the fastest growing firms to -.78 among the biggest job losers. But during the second period, when the same firms are kept in each quintile, there is little difference among quintiles. Firms which were the fastest growing in the first period display average growth in the second, as do firms which were the slowest growing. Growth in the second period appears to be independent of the growth rate in the first period, on average ${ }^{17}$.

For the 370,000 firms included in the sample, the correlation between the log of the employment change in the two periods was $0.16^{18}$. Thus, generally speaking there is a small degree of association between employment growth in one period, and that in the next.

16 These years were selected because consistent data on the LEAP file is available for the 1983 to 1989 period. The longitudinal series was broken in 1989 (see appendix for explanation), and prior to 1983 a different algorithm was used to convert payroll to employment.

17 These are averages for each quintile. Some of the fastest growing firms in period one will be fast growing in period two, but some will be large job losses as well. They are likely to be distributed as all firms are distributed in the second period.

18 For each of the 370,000 firms in the sample the $\ln [E(86) / E(83)]$ was correlated with $\ln [E(89) / E(86)]$. No statistical test was performed to determine if the value was significantly different from zero, since with such a large sample it would be. Since deaths were included in the 86 to 89 period, the change in the second period $[\mathrm{E}(89) / \mathrm{E}(86)]$ could take on the value 0 , and the ln would be undefined. When this occurred, the 0 was replaced by a very small number $(.000001)$ to allow the computation to procede. 
Chart 6: Employment Growth in 1983-86 and 1986-89, by Quintile Keeping the Same Companies in the Quintiles in Both Periods

-- Size 0-19 --

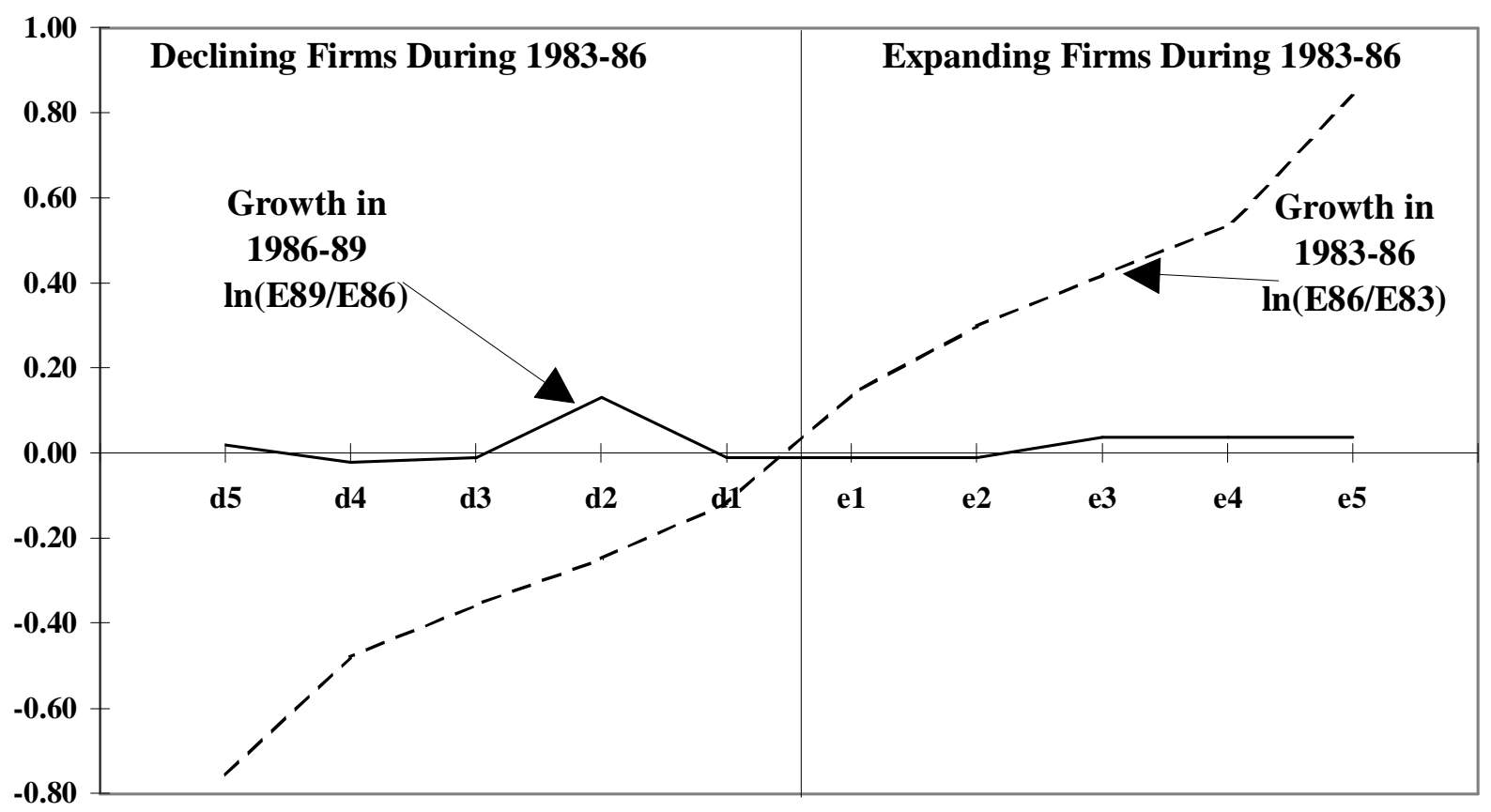

-- Size 20-99 --

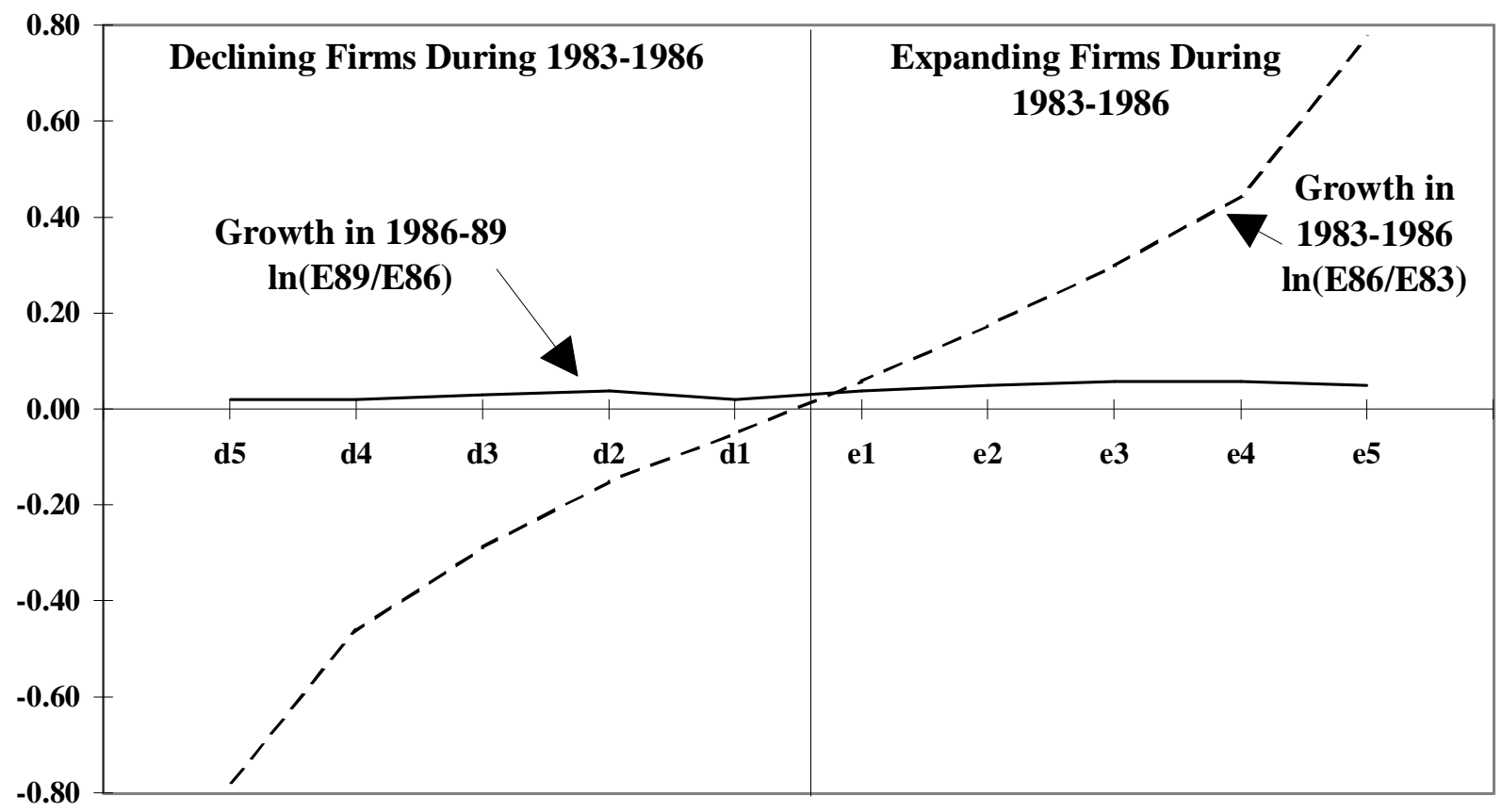


Chart 6: Employment Growth in 1983-86 and 1986-89, by Quintile Keeping the Same Companies in the Quintiles in Both Periods (Cont'd)

-- Size 100-499 --

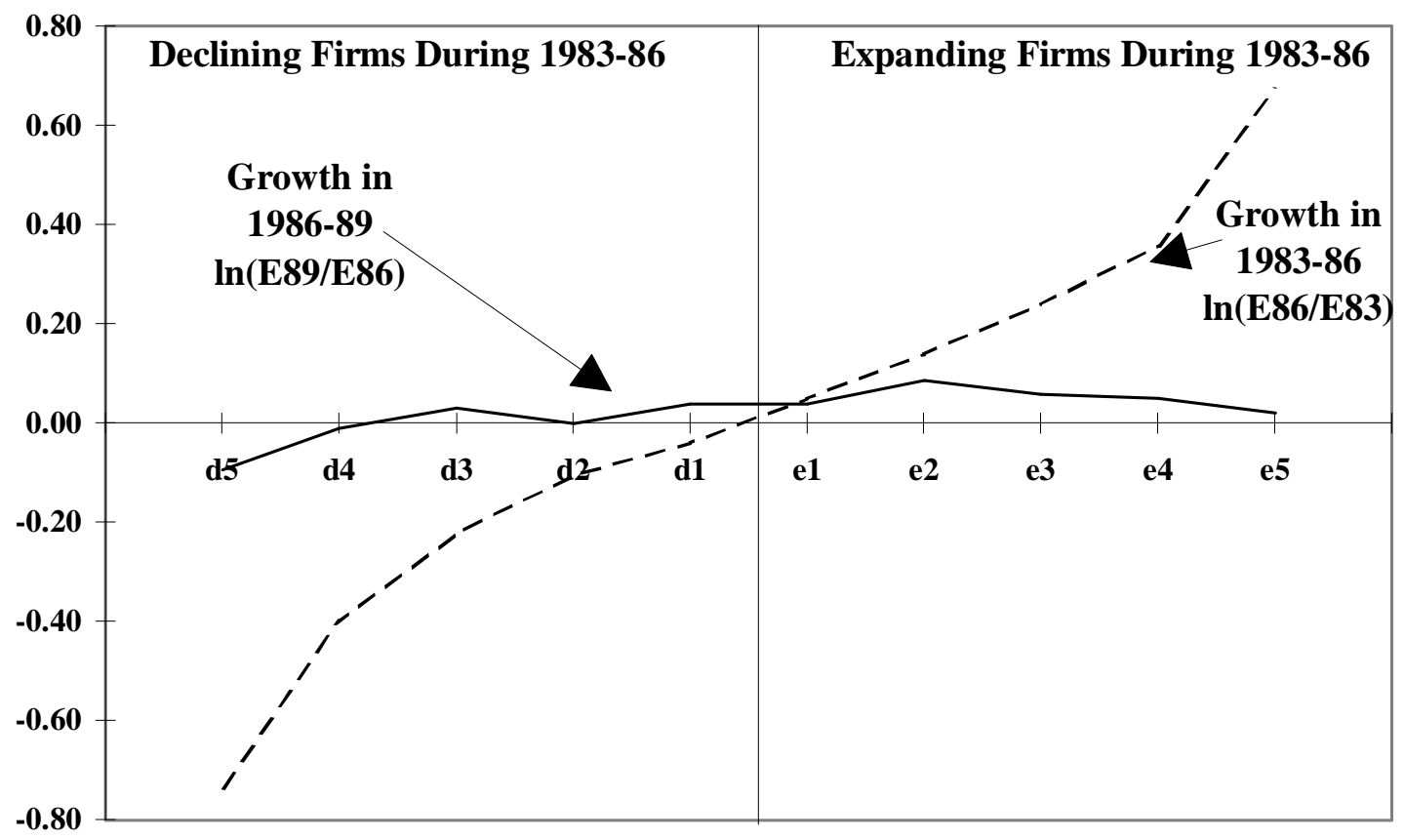

-- Size $500+--$

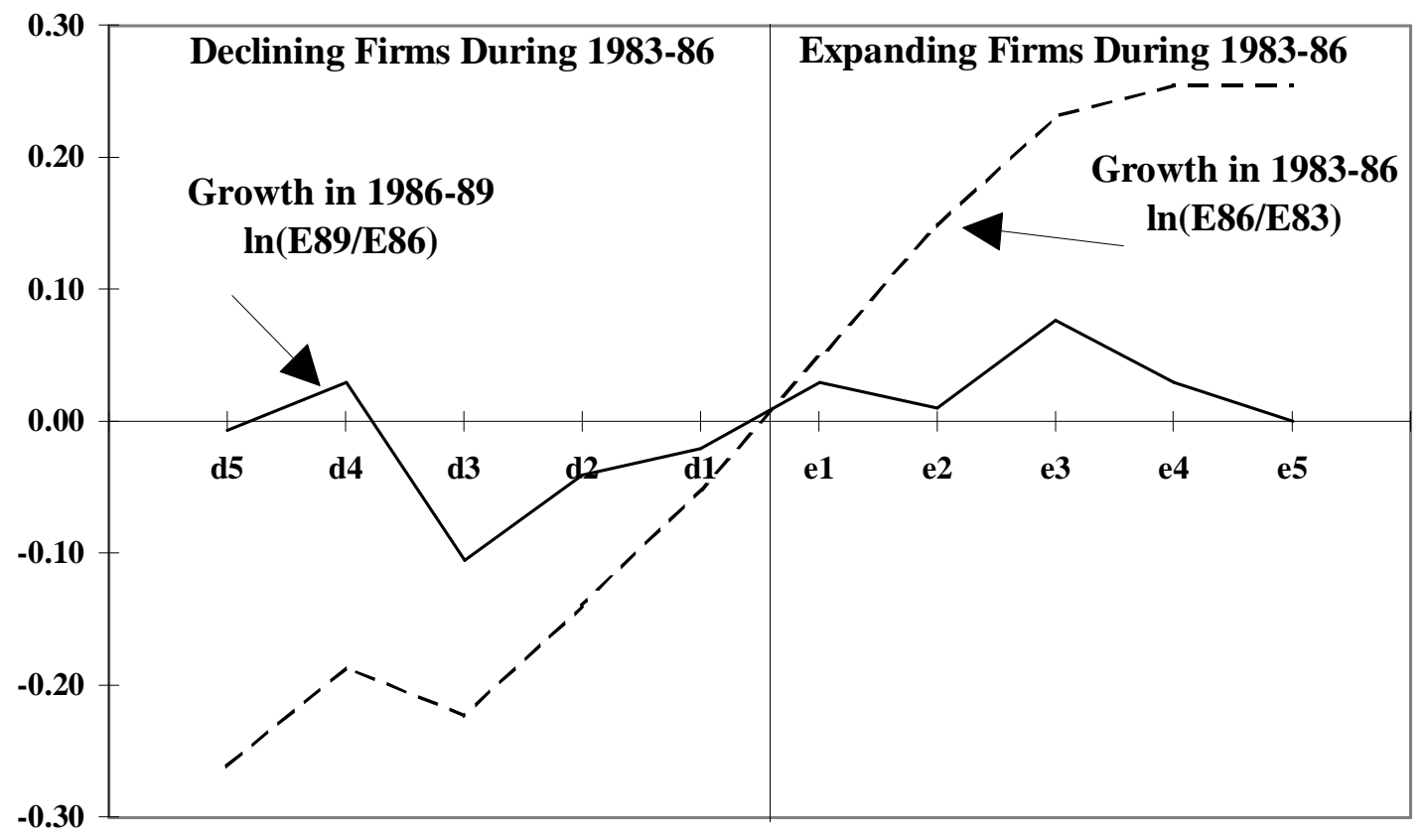


Another means of testing the association between the growth in the two periods is to run a regression to determine how good a predictor the growth in the first period is of that in the second. The equation is simply: $\ell n(\mathrm{E} 89 / \mathrm{E} 86)=\mathrm{B}_{0}+\mathrm{B}_{1} \ell n(\mathrm{E} 86 / \mathrm{E} 83)$, where $\mathrm{E} 89$ is employment during 1989, and so on. Growth in the second period ( $\ell n$ [E89/E86]) is simply expressed as a function of that in the first ( $\ell n$ (E86/E83). The coefficient of interest is $\mathrm{B}_{1}$, which is an estimate of the elasticity between the growth in the two periods. Normally one would use micro-data for the 370,000 firms in the sample to run this regression, but $\ell n(\mathrm{E} 89 / 86)$ will be undefined for firms which disappear during the second period, as E89 will be zero. Thus, after rank-ordering by growth during 1983-86, 25 grouping of firms were calculated for both expanding and declining firms and growth rates in both periods determined for each of the 50 groups. This gives 50 observations in the regressions. Four regressions were run, one for each size class. The values of $B_{1}$ were:

$\begin{array}{lcccc}\text { SIZE CLASS: } & \mathbf{0 - 1 9} & \mathbf{2 0 - 9 9} & \mathbf{1 0 0 - 4 9 9} & \mathbf{5 0 0 +} \\ & & & & .085 \\ \mathrm{~B}_{1} & .007 & .019 & 3.4 & .167 \\ \mathrm{t} & 0.3 & 1.4 & .0\end{array}$

The elasticity between the growth rates in the two periods ranges from .007 for small firms, to .167 for large, and is monotonically increasing. It is, however, not significantly different from zero for firms under 100, indicating independence between the growth rates in the two periods in these size classes. Among large firms, the value is positive, but still small. Even here, the growth rate in the first period is only very weakly associated with that in the second.

TABLE 8: GROWTH RATE OF EMPLOYMENT FOR FIRMS WHICH WERE CONTINUING DURING 1983 -86, BY QUINTILE*

DECLINING FIRMS DURING

1983-86

QUINTILE

SIZE
AVERAGE,
ALL

FIRMS EXPANDING FIRMS DURING
1983-86

QUINTILE

$\begin{array}{llllll}1 & 2 & 3 & 4 & 5\end{array}$

\section{0-19}

\begin{tabular}{|c|c|c|c|c|c|c|c|c|c|c|c|}
\hline GROWTH, 83-86 & $18.6 \%$ & $-53 \%$ & $-38 \%$ & $-30 \%$ & $-22 \%$ & $-11 \%$ & $15 \%$ & $35 \%$ & $52 \%$ & $71 \%$ & $131 \%$ \\
\hline GROWTH, 86-89 & $2.6 \%$ & $2 \%$ & $-2 \%$ & $-1 \%$ & $14 \%$ & $-1 \%$ & $-1 \%$ & $-1 \%$ & $4 \%$ & $4 \%$ & $4 \%$ \\
\hline \multicolumn{12}{|l|}{$20-99$} \\
\hline GROWTH, 83-86 & $16.0 \%$ & $-54 \%$ & $-37 \%$ & $-25 \%$ & $-14 \%$ & $-5 \%$ & $6 \%$ & $19 \%$ & $35 \%$ & $56 \%$ & $117 \%$ \\
\hline GROWTH, 86-89 & $4.6 \%$ & $2 \%$ & $2 \%$ & $3 \%$ & $4 \%$ & $2 \%$ & $4 \%$ & $5 \%$ & $6 \%$ & $6 \%$ & $5 \%$ \\
\hline \multicolumn{12}{|l|}{$100-499$} \\
\hline GROWTH, 83-86 & $13.1 \%$ & $-52 \%$ & $-33 \%$ & $-20 \%$ & $-10 \%$ & $-4 \%$ & $5 \%$ & $15 \%$ & $27 \%$ & $43 \%$ & $96 \%$ \\
\hline GROWTH, 86-89 & $3.4 \%$ & $-9 \%$ & $-1 \%$ & $3 \%$ & $0 \%$ & $4 \%$ & $4 \%$ & $9 \%$ & $6 \%$ & $5 \%$ & $2 \%$ \\
\hline \multicolumn{12}{|l|}{$500+$} \\
\hline GROWTH, 83-86 & $2.8 \%$ & $-23 \%$ & $-17 \%$ & $-20 \%$ & $-13 \%$ & $-5 \%$ & $5 \%$ & $16 \%$ & $26 \%$ & $29 \%$ & $29 \%$ \\
\hline GROWTH, 86-89 & $0.8 \%$ & $-0.7 \%$ & $3 \%$ & $-10 \%$ & $-4 \%$ & $-2 \%$ & $3 \%$ & $1 \%$ & $8 \%$ & $3 \%$ & $0 \%$ \\
\hline
\end{tabular}

* INCLUDES FIRMS WHICH EXISTED IN BOTH 1983 AND 1986. QUINTILES ARE ESTABLISHED BASED ON THE VOLUME OF EMPLOYMENT GROWTH DURING 1983-86. THE GROWTH RATES FOR 1986-89 ARE FOR THE SAME FIRMS THAT WERE INCLUDED IN THE QUINTILE DURING 1983-86. DEATHS ARE ALLOWED DURING 1986-89. 
Thus, firms which are high performers over a three year period do only marginally better than average during the subsequent period, in the aggregate. This is true in all size classes, although more so among small than large firms. The observation that a firm is a high performer during the first three year period provides little information regarding its employment creation performance during the subsequent period.

\section{Conclusion}

Jobs are created in large, medium and small firms, just as they are lost in firms of all size classes. However, when considering firms of different sizes, in Canada both gross job gain and job loss, as well as net employment gain are disproportionately located in the small firm sector, no matter which measure of sizing is used, and whether it is evaluated in the short or long run. This is true for most industrial sectors, and is also true for the growth in payroll as well as the growth in employment. While there may have been some changes in the relative wages or hours worked in small and large firms over the past decade, they have not been sufficiently large to account for the difference in employment growth performance between the small and large firm sectors, at least for the commercial economy as a whole.

Much of this difference in growth rates between the sectors appears to be related to the influence of births on employment growth. When considering only existing firms (i.e. excluding births), much of the difference in net employment growth between the small and large firm sector disappears.

Job gain (and loss) is quite concentrated among relatively few firms in most size classes. This is true for both short and longer-run job gains and losses. For example, among continuing small firms, $5 \%$ of the companies accounted for $43 \%$ of job gain over a three year period; another $3 \%$ accounted for $34 \%$ of the job loss. Concentration tends to be somewhat greater among mid-sized companies, and lower among large firms. The major point, however, is that even when excluding births and focusing on continuing firms, there are very few "typical" firms that grow at the average rates of the kind reported in the studies of employment growth by firm size. While the findings of these studies, including the ones summarized in this paper, are important, it must be remembered that there is tremendous variation in growth within size classes that is obviously related to factors other than size. There are a number of large firms that create a significant share of employment; it was noted that the top performing large firms (accounting for $30 \%$ of large firm employment) out-performed the majority of small continuing firms in terms of job creation.

There are obviously numerous factors other than size that influence employment gains or losses. Baldwin et al (1994) have started the process in Canada of looking to other factors that may be linked with growth, including firm strategies regarding innovative activity, training, capital structure, marketing and others. They note that product and/or process innovation appears to be the most important determinant of growth among small and medium sized firms.

Finally, on the correlation of employment change in firms over two three-year periods suggests that the knowledge that a firm is a fast grower over one period is of only limited value in determining growth in the second period. This is particularly true among small firms. Thus, although employment growth and decline is highly concentrated in the cross-section, it does not appear to be so longitudinally. It has been known for some time that there was a large transitory 
component in the employment growth patterns of individual firms associated with the regression to the mean phenomenon. These results suggest that firms which do well during one period are replaced to some considerable degree by others in the subsequent period. 


\section{Appendix 1: The Leap Data Base}

\section{a) The LEAP Universe}

LEAP is a company level file, the company being defined as the legal entity that reports to Revenue Canada for taxation purposes.

The target population of LEAP is every employer in Canada whether incorporated or not. This universe consists of every business that issued a record of employment earnings for tax purposes (a T4 slip). In Canada employing business are required to register with Revenue Canada using payroll deduction accounts (PD accounts) and issue to each of their employees a T4 slip that summarizes earnings received in the year. This process creates a link between the employee and the company through the payroll deduction account. This link is the backbone of LEAP, and the reported payroll allows estimates of annual employment to be made.

The self employed that do not draw a salary are not included in this universe, and thus are not counted in LEAP. Businesses comprised solely of individuals or partnerships who do not draw a salary are also excluded from LEAP.

PD accounts are the primary means by which the business register identifies new businesses. When a new PD account if reported by Revenue Canada, the BR assesses whether this is a new business, or a PD that belongs to an already existing business. Further testing is done throughout the production of the files to ensure that this distinction is made. There is also testing done to ensure that continuing businesses that see their business register identification number change from one year to another are not classified as deaths and births, but remain classified as continuing (more on this later).

In 1992 there were 980,883 PD accounts representing 925,221 separate companies (legal entities). Hence, most legal entities have a single PD. This is certainly true for small and medium sized firms, the topic of this paper.

\section{b) Establishing the SIC and Payroll of a Company at the Provincial and National Level}

The dominant industry (SIC) and total payroll for each company (legal entity) is established both at the provincial and national level. This allows analysis to be conducted at both these levels of geography. The dominant SIC of a company is based on the industrial classification of its employees. This information comes from the Statistics Canada monthly establishment survey of payrolls and hours (SEPH), which assigns industry codes at the establishment level. A company is assigned the industry code which is dominant among the employment in the establishments (i.e. an employment weighted dominance determined).

There is some concern that assigning industry codes at this higher (company) level will introduce error in the industry coding, since many large companies are multi-establishment, multi-industry entities. To determine the impact of assigning industry codes at the company rather than establishment level, a comparison of the codes assigned employment under the two regimes (i.e. 
at the company and establishment levels) was done. For the economy as a whole, the impact was relatively small. When industry was coded at the company level as described here, 95.3\% of employment had the same 3 digit SIC code as when industry was determined at the establishment level. Particular industries in which there is substantial vertical integration, such as forestry and petroleum, may downplay significant differences in the codes. For example, in the case of forestry, $59 \%$ of workers received the same 3 digit SIC code when industry was assigned at the company and establishment levels. In general assigning the industry code at their company level is not an issue. See Heath, Diversification Patterns of Canadian Industry, Implications of Classifying Canadian Businesses by their Leading Industry of Employment (1990). In particular industries the coding can be quite different at the company and establishment levels. In these cases one must interpret the results as relating to workers who work in companies which are primarily involved in producing products in one particular industry, rather than workers who work in a particular SIC.

\section{c) Average Labour Units}

An average labour unit (ALU) measure of employment is calculated for every business at the province level by dividing the provincial payrolls of a business by a conversion factor derived for the SEPH survey. This operation is described in the Statistics Canada publication 18-501 "Developing a Longitudinal DataBase on Businesses in the Canadian Economy: An Approach to the Study of Employment". Recently (starting with the 1989 data) the methodology has been enhanced: conversion factors are produced at the province / 3 digit SIC and size level (before all sizes were treated the same way). The resulting employment measure (the ALU) is conceptually identical to the employment measure from SEPH, which is an average annual head count of employees, and is available for every employing business in Canada. This measure is not a full time equivalent count, and does not distinguish between part-time and full-time work.

Each year analysis of the estimates is done by comparing the LEAP ALU estimates with the employment estimates of SEPH, and of the Statistics Canada monthly Labour Force Survey (LFS). In these comparisons it is typically found that levels are different, with LEAP somewhere between SEPH (low) and LFS (high), but that trends are similar at the major industry group level. The differences in level can often be ascribed to conceptual differences in the surveys.

\section{d) Creating a Longitudinal File}

Annual files with records that represent legal entities within a province or nationally are created in the way just described. Each record has information on the SIC, payroll, and an estimate of average annual employment (ALUs). The next step in this process is to create a longitudinal file of the type required to carry out analyses of employment dynamics. The legal entity number (called an 's' number) in the business register is the foundation for this longitudinal linkage. A comprehensive longitudinal file that spans many years is created by linking on this number.

Because a new business register was created in Statistics Canada and implemented in 1989, the LEAP file has a break at that point. A company is not defined in exactly the same way in the new $\mathrm{BR}$ as in the old, and hence the longitudinal series is interrupted at that point. Two files were created for 1989, one on the basis of the old definitions of companies, one employing the new. 
We are currently working on creating a single longitudinal file spanning 1989 by mapping the new companies onto the old.

Considerable methodological verification takes place to ensure that the longitudinal linkage of the companies is reliable. In particular, "phony" births and deaths are identified by using a "labour tracking" methodology recently introduced. This approach essentially tracks workers from one year to the next, through record linkage methods. It is then possible to determine if the worker stays with the same company, or moves to another. In this process, we look for situations where the majority of the workforce has moved collectively from one firm to another. Such movements suggest that the two firms may well be the same firm, and that what occurred on the business register was in fact the false creation of a death and a birth, when there should have been one continuing firm. This is an example of the manner in which the labour tracking is used.

More information on Labour Tracking can be found in Development of Longitudinal Panel Data from Business Registers: Canadian Experience by Baldwin, Dupuy and Penner (1993), Statistical Journal, UN Economic Commission for Europe.

Since the longitudinal file is at the legal entity level, even with labour tracking it is possible that a company with the same ' $s$ ' number is a different entity from one year to the next due to mergers or buyouts. Because of these changes, it is difficult to know when a company ceases to be the same company and takes on a new form as a result. The longer the period over which companies are tracked longitudinally, the more likely this is to be a problem. When these questions were investigated in more detail it was determined that the bulk of these changes were taking place between larger firms. This would have a tendency to increase gross creation and destruction rates in larger size categories.

We believe that with respect to the analysis of job creation by firm size, the possible biases introduced by mergers and acquisitions would tend to be small and, if anything, tend to underestimate our major finding. This is because only mergers and acquisitions that involve two firms that are in different size classes would have any effect on the findings. Mergers among firms within a size class would have no effect, since the employment would still be identified as having been associated with, say, a large firm. Many mergers would be among large firms. And if a smaller firm is acquired by a larger, which is often the case, this would be seen as a death in the small firm class, and employment expansion in the large. Thus, if anything such transactions would tend to apparently increase employment creation in the large firm class. 


\section{Bibliography}

Baldwin, J., (1995); Job Growth and Job Quality; Paper prepared for the Ontario Ministry of Finance, Mimeo, Statistics Canada.

Baldwin, J., Chandler, W., Le, C., Papailiadis, T., (1994); Strategies for Success, A Profile of Growing Small and Medium-Sized Enterprises in Canada, Statistics Canada Publication No. 61-523, Ottawa.

Baldwin, J. and Gorecki, P.K. (1990); Structural Change and the Adjustment Process: Perspectives on Firm Growth and Worker Turnover, Economic Council of Canada, Statistics Canada, Ottawa.

Baldwin, J., Dupuy, R., and Penner, W., (1993); Development of Longitudinal Panel Data from Business Registers: Canadian Experience, the Statistics Journal, UN Economic Commission, Autumn.

Baldwin, J. and Picot, G., (1995); Employment Generation by Small Producers in the Canadian Manufacturing Sector, Research Paper \#70, Analytical Studies Branch, Statistics Canada, Ottawa.

Birch, David L. (1987); Job Creation in America: How our Smallest Companies Put the Most People to Work, New York: The Free Press.

Birch, David L. (1979); The Job Creation Process, 1979, Unpublished Report, MIT Program on Neighborhood and Regional Change.

Blanchflower, D.G., and Burgess, S.M., (1994); Job Creation and Job Destruction in Britain, 1980-90, Discussion Paper No. 912, Centre for Economic Policy Research.

Brown, C., Hamilton, J., Medoff, J., (1990); Employers Large and Small, Harvard University Press, Cambridge, Mass.

Davis, S.J., Haltiwanger, J., Schuh, S. (1993); Small Business and Job Creation: Dissecting the Myth and Reassessing the Facts, Unpublished Report, University of Chicago, University of Maryland, Federal Review Board.

Davis, S.J., Haltiwanger, J., (1993); Gross Job Creation, Gross Job Destruction and Employment Reallocation, Working Paper No. 3728, Cambridge, Mass., National Bureau of Economic Research, June.

Davis, S., Haltiwanger, J., Schuh, S., (1994); Gross Job Flows in U.S. Manufacturing, U.S. Department of Commerce Bureau of the Census, Center for Economic Studies, Washington. 
Heath, J., (1992); Diversification Patterns of Canadian Industry Implications of Classifying Canadian Businesses by their Leading Industry of EmploymentStatistics Canada, Ottawa.

Industry Canada, (1994); Growing Small Businesses, Communication Branch, Industry Canada, Ottawa.

Industry, Science and Technology Canada (1991); Small Business in Canada, Minister of Supply and Services, Ottawa.

Leonard, J.S., (1986); On the Size Distribution of Employment and Establishment, Working Paper No. 1951, National Bureau of Economic Research.

Loveman, G., Sengenberger, W., (1991); The Re-emergere of Small Scale Production: An International Comparison, Small Business Economics 3:1 - 37.

Ministry of Industry, Trades and Technology (1987); The State of Small Business in Ontario, Ontario Government, Toronto.

Morissette, R., (1993); Canadian Jobs and Firm Size: Small Firms Pay Less?, Canadian Journal of Economics, February, XXVL, No.1.

OECD, (1985); Employment in Small and Large Firms: Where have the Jobs come From?, Employment Outlook, Paris.

Picot, G., (1992); Workers on the Move: Permanent Layoffs; Perspectives on Labour and Income, Autumn, Statistics Canada, Ottawa.

Picot, G., Baldwin, J. and Dupuy, R., (1995); Small Firms and Job Creation, A Reassessment, The Canadian Economic Observer, January, Catalogue No. 11-010, Statistics Canada.

Revelli, R., (1994); Statistics on Job Creation: Issues in the Use of Administrative Data, Paper prepared for OECD meeting on Job Creation and Loss.

Statistics Canada (1989); Developing a Longitudinal Database on Businesses in the Canadian Economy, An Approach to the Study of Employment, Publication No. 18-501, Ottawa.

Wannell, Ted (1991); Trends in the Distribution of Employment by Employee Size: Recent Canadian Evidence, Research Paper No. 39, Analytical Studies Branch, Statistics Canada. 